\title{
Bakeout Effects on Dynamic Response of Spaceflight Cables
}

\author{
Kaitlin S. Spak* \\ Virginia Polytechnic Institute and State University, Blacksburg, Virginia 24060 \\ Gregory S. Agnesì \\ Jet Propulsion Laboratory, California Institute of Technology, Pasadena, California 91101 \\ and \\ Daniel J. Inman \\ University of Michigan, Ann Arbor, Michigan 48109 \\ DOI: $10.2514 / 1 . \mathrm{A} 32780$
}

\begin{abstract}
Spaceflight cables are investigated to determine the effect of bakeout on their dynamic response, including resonant frequencies and damping ratios. The addition of cable harnesses to spacecraft structures can affect the dynamic response of the entire structure, especially for lightweight structures with high cable mass ratios. Bakeout, a heat and vacuum treatment that spaceflight components must undergo, may change the dynamic stiffness of flight cables and thus the dynamics of the cabled host structure. Bakeout effects are examined by experimentally identifying natural frequencies and damping values for spaceflight cables before and after the bakeout process. After bakeout, the first natural frequency decreases by an average of $14 \%$ for all single-strand cables and by $24 \%$ for multistrand cables. The second natural frequency decreases by 8 to $17 \%$ for all cables. Bakeout also increases the damping percentage for single and multistrand cables. These results show that bakeout affects the dynamic response of spaceflight cables significantly and should be taken into account when using cable data for design purposes.
\end{abstract}

\section{Nomenclature}

$A=$ cross-sectional cable area, $\mathrm{m}^{2}$

$d=$ wire diameter, $\mathrm{m}$

$E=$ modulus of elasticity, $\mathrm{N} \cdot \mathrm{m}^{2}$

$E I=$ bending stiffness, $\mathrm{N}-\mathrm{m}^{2}$

$f=$ applied external force, $\mathrm{N}$

$G=$ modulus of rigidity, $\mathrm{N} / \mathrm{m}^{2}$

$I=$ area moment of inertia, $\mathrm{m}^{4}$

$K_{c}=$ curvature, $\mathrm{m}^{-1}$

$r=$ wire layer radius, $\mathrm{m}$

$t=$ time variable, $\mathrm{s}$

$w=$ beam displacement, $\mathrm{m}$

$x=$ spatial variable, $\mathrm{m}$

$\beta=$ lay angle, $\mathrm{rad}$

$\kappa=$ shear coefficient

$\mu \quad=$ interwire friction coefficient

$\rho=$ cable density, $\mathrm{kg} / \mathrm{m}^{3}$

$\sigma_{T}=$ tensile stress in wire before bending, $\mathrm{N} / \mathrm{m}^{2}$

$\varphi=$ wire location angle, rad

\section{Introduction}

C HARACTERIZATION of cable dynamics has become important to the design of space structures and satellites as cable mass percentages have increased [1]. Material science advances have created lighter-weight structural materials, and increasingly complex

Received 25 July 2013; revision received 12 January 2014; accepted for publication 12 January 2014; published online 8 May 2014. Copyright (C) 2014 by the American Institute of Aeronautics and Astronautics, Inc. The U.S. Government has a royalty-free license to exercise all rights under the copyright claimed herein for Governmental purposes. All other rights are reserved by the copyright owner. Copies of this paper may be made for personal or internal use, on condition that the copier pay the $\$ 10.00$ per-copy fee to the Copyright Clearance Center, Inc., 222 Rosewood Drive, Danvers, MA 01923; include the code 1533-6794/14 and \$10.00 in correspondence with the CCC.

*Ph.D. Candidate, Mechanical Engineering Department, 105 N. Wilson 102; currently Jet Propulsion Laboratory, California Institute of Technology, Pasadena, CA 91101. Student Member AIAA.

${ }^{\dagger}$ Research and Development Engineer, 3850, 303-400D. Associate Fellow AIAA.

Fepartment Chair, Aerospace Engineering Department, 3064 FXB. Fellow AIAA. instrumentation requires more wires and has increased the size and number of cables on any given space structure. In contrast, the conductive components of signal and power wires have not advanced; comparatively, heavy copper and aluminum are still used as conductors, and electromagnetic interference (EMI) shielding is generally metal as well. These trends combine to result in a significant increase in cable mass as a percentage of the total spacecraft mass. Current craft design assumes a $10 \%$ cable mass, with some structures' cable masses being as high as 30\% [2]. Figure 1 shows a space structure with cables distributed throughout the ${ }^{-}$structure as is typical, connected to the host structure at multiple points with cable ties. Currently, cables are either neglected entirely in vibration models or are modeled as nonstructural lumped mass, for which the sum mass of the distributed cables is added to the total structure mass at the center of gravity of the structure model $[3,4]$. However, with the increased cable mass percentage and lightweight base structure, cables now need to be modeled as more realistic structural mass with the capacity to affect the dynamic response of the structure as a whole. These distributed models require knowledge of the cable properties, and the bending stiffness value for a spaceflight cable is an important parameter in the structural model.

Cable dynamics have been studied for decades, but the investigation of spaceflight cables so far has been limited to cables constructed for the purpose of testing. Cables that are constructed for actual flight must go through additional preparation and testing, including bakeout, a combination of heat and vacuum treatment designed to expedite the initial outgassing of flight hardware for contamination control [5]. Anecdotal reports from cable technicians suggest that cables seem stiffer after going through the bakeout process, but no study exists to affirm or quantify this difference. Since there is no existing literature on the effects of bakeout on flight cables, and quantification of cable dynamics is important for space structure modeling, this investigation was conducted to determine whether bakeout affects cable dynamics and spacecraft structural models that include cables. Thus, the objective of this investigation is to observe and quantify the effects of bakeout on spaceflight cable dynamics, including changes in natural frequencies and damping effects. Since cable dynamics have only been considered prior to bakeout, knowing that the bakeout process can shift the resonant frequency of the cables and influence damping is an important aspect to include in the design and application of cable harnesses. This study improves the characterization of spaceflight cables by identifying and quantifying the changes in cable dynamic response due to bakeout; these changes 


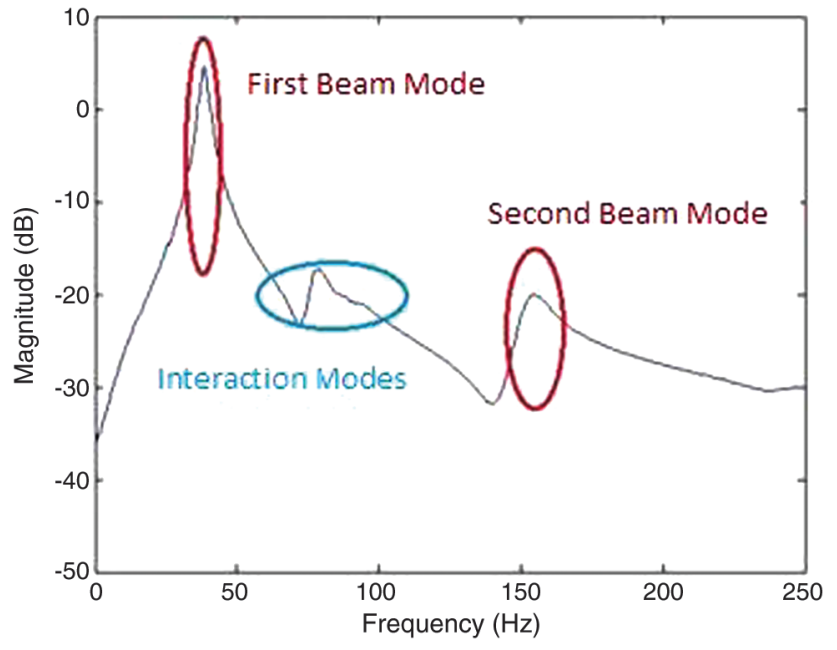

Fig. 1 Wiring detail of instrument on ICE satellite showing distributed cables within, ${ }^{\$}$ attached to host structure with cable ties.

in bending stiffness and damping can now be included in structural models to improve their accuracy.

\section{Background}

\section{A. Cable Terminology}

Before describing the experimental methods used, a discussion of cable terminology is necessary, largely based on Costello's work on wire rope [6]. Cables are made up of a core wire or strand surrounded by layer wires or strands. A wire refers to an individual wire, commonly a twisted pair of conductors wrapped in an insulating material, and a strand is a collection of multiple wires twisted in a helical pattern. A single-strand cable is a single wire for the core with additional wires making up the outer layers of the cable in a single helix shape, while a multistrand cable has a strand for the core and is wrapped with more strands. The cores of the layer strands are single helixes, but the layer wires of the layer strands are in a double helix shape. Multistrand cables are more flexible than single-strand cables of the same size and number of wires. Cables are designated by a $m \times n$ description, in which $m$ is the number of strands and $n$ is the number of wires in each strand. Figure 2 a shows a $1 \times 19$ cable, a single-strand cable that consists of one strand with 19 wires in that strand, and Fig. 2 b shows a $7 \times 7$ cable, a multistrand cable that consists of seven $\overline{1} \times 7$ strands.

The lay angle of a cable is the angle that the layer wires make with the core. Cables are right-hand or left-hand lay, which describes the direction in which the wires or strands are wrapped around the core. Cables can be helically twisted, in which case each layer is wrapped in the same direction, or contrahelically twisted, in which case each successive layer alternates the lay direction. After construction, cables may be tie laced and then wrapped with a layer of Kapton tape.

Cables used for the initial investigation were hand twisted and hand wrapped and showed a high degree of build-to-build variability. Based on previous theoretical studies, characteristics of helical cables with more than 19 wires were significantly affected by lay angle [7], so it was important to keep the lay angle constant for each cable section. The cables used for the bakeout comparison were machine manufactured using a planetary machine to ensure a constant lay angle and exact overwrap overlap.

\section{B. Bakeout}

Any cable that will become flight hardware goes through a bakeout treatment. Bakeout is a process that requires both high thermal treatment and near-vacuum pressure. This is so that any volatile gasses will diffuse out before the flight. Bakeout may take anywhere

${ }^{\S}$ NASA ICESat wiring detail image is available online at http://icesat.gsfc .nasa.gov/icesat/photogallery/glas-itgallery.php [retrieved 3 April 2013]. from a few hours to several weeks, depending on the item's intended destination and mission. All components of a space structure must go through bakeout to become flight ready, but components may be baked out separately and assembled in a clean room prior to launch. It is common for cables to be baked out separately from the main structure, which also means that vibration testing usually occurs before cables are added to the structure. This provides further motivation to model the effects of cables on structures since the structure cannot be tested with dirty equipment once it is assembled in a clean room. Common bakeout procedures include planetary protection bakeout, necessary for biological decontamination, and low-Earthorbit bakeout, used for objects that will not be venturing farther than 2,000 km from the Earth's surface. A low-Earth-orbit bakeout was used for this study, as cabling on satellites is of particular interest, and satellites are maintained at low Earth orbit.

\section{Effect of Cables on Host Structures}

Natural frequencies and damping ratios can be determined by measuring the frequency response function (FRF) of a structure, which relates the amplitude of vibration to an input force [8]. The addition of a cable to a host structure significantly changes the dynamic response of the structure by changing both the natural frequencies and amount of damping and thus the FRF data [4]. This is evidenced by the experimental data shown in Fig. 3 , which compares the FRFs of a bare aluminum beam with the FRF of the same aluminum beam with a cable attached to it. For this case, the cable made up about $7 \%$ of the total structure mass, which is within the typical range for cable mass percentage on space structures. To correctly control the structure and avoid failure due to vibration events such as launch, it is important to be able to predict these altered frequencies and amplitude changes. Modeling cables as structural mass with accurate bending stiffness values for the cables should improve the predictive ability of cabled structural models. If the bakeout process is indeed affecting the bending stiffness of space flight cables, the changed stiffness value could lead to inaccurate models. Past research has shown that cable overwrap and jacketing leads to increased shear and viscoelastic effects that lead to greater internal cable damping [9], so it is reasonable to question whether bakeout is affecting these parameters and thus affecting the damping and dynamic response of the cables.

\section{Theory}

Cable bending stiffness is an important property for modeling cables as dynamic structural mass when cables are modeled as beams [10]. Background research confirms that bending stiffness must be included for an accurate cable model, and research conducted by the Air Force Research Laboratory Space Vehicles Directorate shows that including cables as lumped mass is no longer adequately accurate and that the interaction between cable and structure must be considered $[4,11]$. Research also shows that a beamlike model that includes shear effects and bending stiffness can model cable behavior reasonably well [12]. Thus, modern cable models depend on an accurate bending stiffness value. In this case, of interest is the bending stiffness term $E I$ of the equation of motion for a cable modeled as a beam, where dotted variables denote time derivatives and primes denote spatial derivatives:

$$
\rho A \ddot{w}(x, t)-\frac{\rho E I}{\kappa G} \ddot{w}^{\prime \prime}(x, t)+E I w^{\prime \prime \prime \prime}=f(x, t)
$$

Damping is not yet taken into consideration, although there is evidence that a carefully calculated bending stiffness value can incorporate some level of internal damping for cables [13]. Whereas bending stiffness for a solid homogenous beam of constant cross section is straightforward, calculation of the bending stiffness value for a cable is significantly more difficult, and experimental data are required. First, the modulus of elasticity for a cable depends on the constitutive materials as well as the interwire friction within the cable, values that are nearly impossible to measure and difficult to estimate. The moment of inertia of a stranded cable is more complex than the 


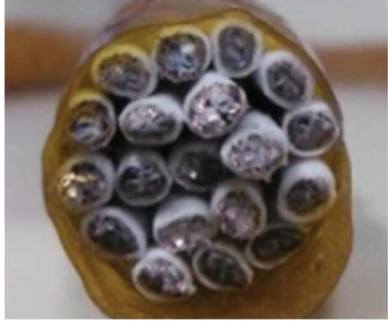

a)

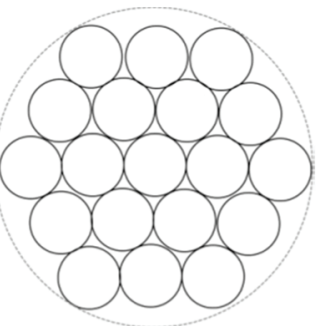

Fig. 2 Examples of spaceflight cables and their associated wire layouts.

b)
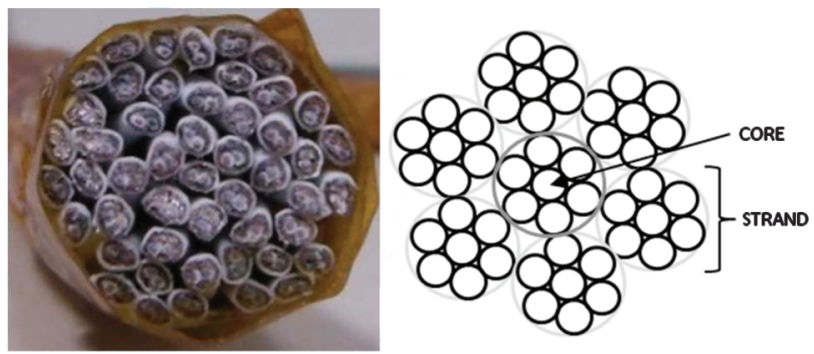

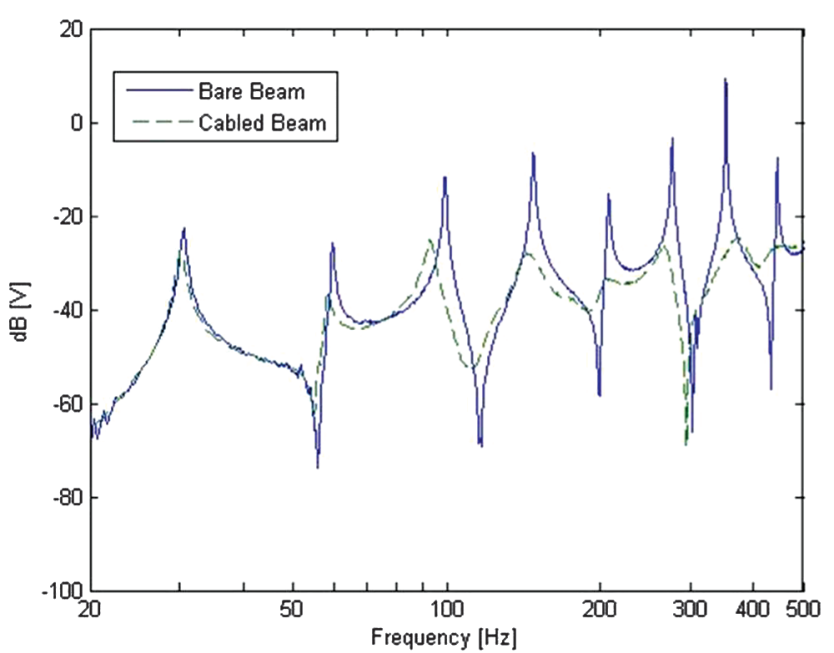

Fig. 3 Comparison of frequency response functions for a bare beam and a cabled beam, showing the nonuniform effect of cabling on dynamic response.

moment of inertia of a solid circular beam, and the bending stiffness actually changes depending on the cable curvature and whether the individual wires are sticking or slipping [10]. According to Papailiou's work on aluminum-conductor, steel-reinforced (ACSR) transmission cables [10], a multilayer conductor has a maximum bending stiffness when all wires are in the stick state and a minimum bending stiffness when all wires have slipped. Cable bending stiffness can be calculated as the sum of bending stiffnesses of each individual wire, calculated using the following equations:

$$
\begin{gathered}
E I_{\text {base }}^{\text {wire }}=E_{\text {wire }} * \frac{\pi d^{4}}{64} \cos \beta \\
E I_{\text {stick }}^{\text {wire }}=E_{\text {wire }} A *(r \sin \phi) \cos ^{3} \beta \\
E I_{\text {slip }}^{\text {wire }}=\sigma_{T} A\left(e^{(\mu * \sin (\beta) * \phi)}-1\right) * \frac{r \sin \phi \cos \beta}{K_{c}}
\end{gathered}
$$

These equations are summed over all wires to give the corresponding conductor bending stiffness at a certain conductor cross section. Cable geometry is shown with lay and location angles identified for a $1 \times 7$ cable in Fig. 4 .

When the cable is in a sticking state, the bending stiffness is given in Eq. (5), and when in a slipping state (when bent past the critical curvature), the bending stiffness is a function of curvature and cable tension and is given in Eq. (ㅁ):

$$
\begin{aligned}
& E I_{\text {max }}=\sum E I_{\text {base }}^{\text {wire }}+\sum E I_{\text {stick }}^{\text {wire }} \\
& E I_{\text {min }}=\sum E I_{\text {base }}^{\text {wire }}+\sum E I_{\text {slip }}^{\text {wire }}
\end{aligned}
$$

The cables in this study, although much smaller in diameter, share the same basic construction of a core wire surrounded by layer wires and have the same geometric layout as a stranded ACSR cable, as well as having similar stick-slip behavior due to friction between the wires. Although Papailiou provides a starting point for more accurate cable bending stiffness estimation based on these similarities, there are limitations to these equations that make experimental investigation necessary. First, the equations were developed for solid metal wires in a $1 \times 7$ single-strand configuration; the inclusion of EMI shielding and viscoelastic insulation material around each wire, both of which are present on wires used for spaceflight, is not taken into account. The $E_{\text {wire }}$ value in Eqs. (2) and (3) is a single value for pure materials, but for a wire comprising a conductive core, EMI shielding, and insulation, the value of $E$ can only be estimated using a rule of mixtures approach to give an upper and lower bound. In addition, the coefficient of friction between wires is difficult to determine and is dependent on the outer wire material and radial inward pressure of each wire due to overall tension in the cable. Finally, once again, the effect of bakeout has not been considered, and the modulus of elasticity or moment of inertia of a baked wire or baked cable might be different due to temperature and vacuum effects. Therefore, this experimental study was conducted to provide concrete values for cable bending stiffness and a comparison between cable stiffness before and after bakeout. Table $\underline{1}$ provides the theoretical upper and lower bounds for the bending stiffness values for each of the four cable sizes tested, although it should be noted that these are rough

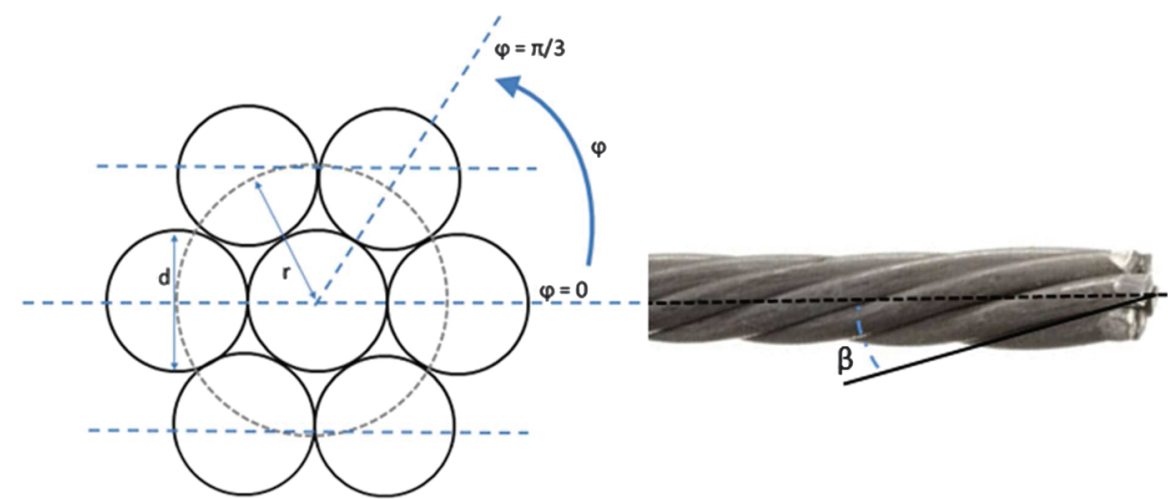

Fig. $41 \times 7$ cable end and side view with equation parameters $d, r, \varphi$, and $\beta$ identified. 
Table 1 Bending stiffness bounding values calculated for four cable types

\begin{tabular}{lcc}
\hline \hline & \multicolumn{2}{c}{ Bending stiffness, $\mathrm{N} \cdot \mathrm{m}^{2}$} \\
\cline { 2 - 3 } Cable & Lower bound & Upper bound \\
\hline $1 \times 7$ & 3.0 & 3.5 \\
$1 \times 19$ & 21.8 & 26.0 \\
$1 \times 48$ & 168.4 & 202.7 \\
$7 \times 7$ & 101.1 & 187.7 \\
\hline \hline
\end{tabular}

estimates based on the assumption that a conducting wire can be modeled as a concentric fiber matrix and that the equations developed for ACSR cables are valid for similarly stranded electrical cables.

\section{Experimental Setup and Methods}

The unbaked cables were excited with a shaker, and the dynamic response was measured with a laser vibrometer. This noncontact measurement method allowed for minimal mass loading on the cable since no accelerometers were required for data collection. A force transducer was used at the driving point to measure the input force, and the vibrometer collected the response information from the driving point for single-point evaluation. Then, the cables were baked out and retested using the same method to produce data for comparison. This vibration testing and analysis followed the methods and recommendations of Ewins [14] whenever possible.

\section{A. Initial Investigation and Method Development}

To examine the effect of bakeout, initial experiments were required to develop a reliable method to extract cable frequency and damping information from vibration testing. First, an examination of a variety of cables was conducted to determine how to measure the dynamic response of the cable itself and what type of cable would represent a typical spaceflight cable and produce repeatable frequency response functions to ensure a valid and meaningful comparison between the treated and untreated cables. Preliminary experiments were run on these spaceflight cables to determine what factors and parameters would need to be controlled [15]. A standard run was developed to acquire clear frequency response functions that identified the first and second modes, and these methods were used on a new set of cables manufactured more consistently. Cables ranging in size from $1 \times 7$ to $1 \times 48$ were found to be typical, and copper wire with tinned copper EMI shielding and Tefzel insulation with lacing ties and Kapton overwrap was common.

The dynamic response of the cable was determined by exciting the cable through a tensioned wire using a modal shaker and measuring

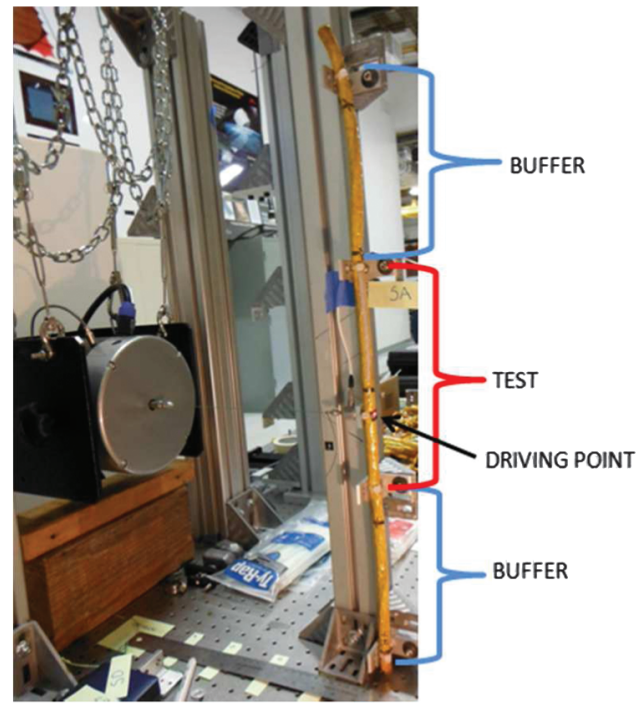

Fig. 5 Test setup for cable testing. the response both at the driving point and along the cable with a Polytec PSV-400 laser vibrometer. A test fixture was created that held the cable in place vertically using TyRap cable ties and Thomas and Betts TC-105 cable tie loops. This method was chosen both for its similarity to a pinned boundary condition and because this is the most common method of attachment for cables on actual structures, as evidenced in Fig. 1. This attachment method had also been used in previous studies $[1 \overline{1} 1,12]$ with good results. The attachment points were mounted away from the vertical support to ensure minimal interaction with the host structure, and the shaker was suspended to isolate the excitation vibrations. Buffer zones above and below the region of interest were included in the test setup to mitigate end effects and simulate the real-life scenario of a cable attached at multiple points. The test setup, with test section and upper and lower buffer zones identified, is displayed in Fig. $\underline{5}$. Figure $\underline{6}$ shows a closer view of the driving point attachment, where the tensioned wire from the shaker attached to the load cell and then to the cable through another TC-105 mounting tab.

The next step was to develop a standard run to ensure that cables would be tested in the same way for each trial before and after bakeout. Initial experiments were conducted to determine which factors would affect the frequency response for the cables; excitation method, tension in the cable, zip-tie attachment method, cable orientation, and length and tension of the excitation string were varied individually. Cables were mounted in the test fixture in the same way each time, with a single variable changed each time to observe the effects of changes in the test setup or software on the cable response. Cable tension and cable tie tightness were important factors to keep constant for each test section, while excitation method and excitation string length and tension did not affect the results. Further details of the standard run development are available in [15]. It was also important to keep the static displacement of the cable to a minimum as a precaution, as curvature in the cable would cause wires to slip and thus change the bending stiffness based on the equations of [10]. From these tests, a standard test run was developed, which set standards for a variety of characteristics to be controlled. The standard test run required a $0.254 \mathrm{~m}$ test section bordered by $0.2 \mathrm{~m}$ buffer sections pinned above and below the test section with $8.89 \mathrm{~N}$ of tension in the cable, applied via a hanging weight hung from a hose clamp secured to the cable to distribute the weight evenly. The cable was attached with a cable tie at one end and tensioned with the hanging weight; the remaining attachment points were then secured, and then the weight was removed. The cable ties were fastened with a cable tie gun on the tightest setting, so tension in the cable was maintained after the removal of the weight. White noise excitation

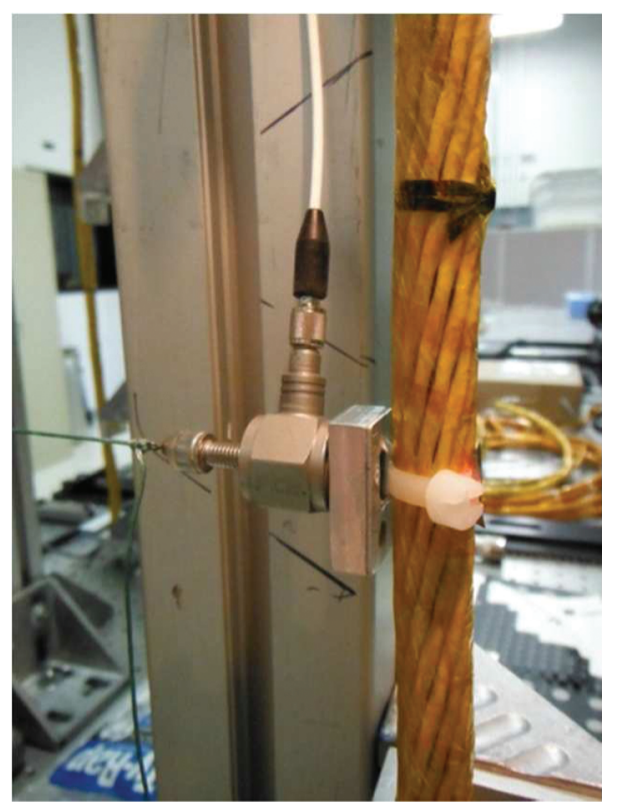

Fig. 6 Attachment of tensioned wire at driving point. 

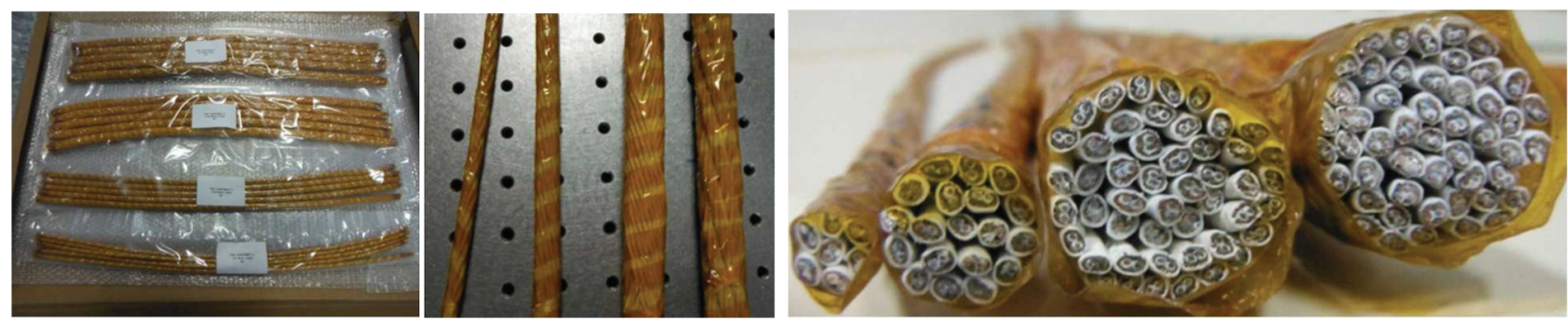

Fig. 7 Cable samples used for the study; from bottom to top and left to right, these are $1 \times 7,1 \times 19,1 \times 48$, and $7 \times 7$.

was applied at 0.3 volts at $8.3 \mathrm{~cm}$ from the bottom of the test section via a $0.24 \mathrm{~m}$ tensioned string at medium $\mathrm{dc}$ offset. The input excitation acceleration corresponded to $\pm 0.155 \mathrm{~g}$ for the largest $(7 \times 7)$ cable and $\pm 0.38 \mathrm{~g}$ for the smallest $(1 \times 7)$ cable; these values are comparable to the measured launch accelerations of $\pm 0.4 \mathrm{~g}$ for STS-41 [16] and are less than the lateral launch acceleration of $\pm 2 \mathrm{~g}$ for the Ariane 5 [17]. The standard test run also dictated a static cable displacement due to excitation string tension of less than $0.6 \mathrm{~mm}$, and all pinned connection points were secured by cable ties tightened to tight setting 5 on a Thomas and Betts cable tie gun. Between each standard run, the cable was removed from the test fixture and reattached for each individual run. A low-pass $5 \mathrm{kHz}$ filter and Hanning window were applied, and 30 averages were taken per test run. All of these features comprised the standard test run to ensure experimental repeatability.

The data acquisition software was set to gather data through $2000 \mathrm{~Hz}$, although only the region from 0 to $500 \mathrm{~Hz}$ was of interest; this kept the amplitude error to less than 5\%.I The PSV VD-08 velocity decoder was used as part of the Polytec software. On each day of testing, the cable response was also scanned once at intervals of 0.9 centimeters, encompassing the entire test section, to visualize the mode shapes and ensure that the cable transverse modes were identified correctly.

The work done to develop the standard run showed that helical cables had a frequency dependence on the orientation of the cable in the test fixture as measured with respect to the coil plane. Contrahelical cables, in which each layer alternates lay direction, were used to eliminate this variation. Contrahelical cables that were machine manufactured were procured to eliminate the build-to-build variability shown in handmade cables used in previous studies of cable dynamics. The cables were made on a planetary machine, tie wrapped every 4-6 inches, and then overwrapped with Kapton tape by machine. The machine-made cables were straighter, fit into the test fixture without torque at the attachment points, and had a more uniform Kapton overwrap. Figure 7 shows the cables used for this study. Five samples each of configurations $1 \times 7,1 \times 19$, and $1 \times 48$ were used to compare single-strand cables as well as five samples of $7 \times 7$ to include a multistrand cable in the comparison. All cables were made of M27500-26TG2T14 wire, a wire commonly used for flight missions.

Table 2 shows the average dimensions of each cable sample for the three samples of each type of cable selected for the bakeout process. Since even the machine-produced cables showed variation from section to section, it was important that the cables be compared individually to determine the bakeout effects. Lay angles varied by less than $1 \mathrm{deg}$ for the $1 \times 48$ and $7 \times 7$ cables, $2.5 \mathrm{deg}$ for the $1 \times 19$ cables, and $3.5 \mathrm{deg}$ for the $1 \times 7$ cables. Mass, length, and diameter measurements were extremely consistent, and negligible mass was lost due to the bakeout process.

\section{B. Unbaked Cable Testing}

At this point, the study of interest truly begins: the comparison of the dynamic response of a cable before and after bakeout treatment. After developing the standard run and method to test each cable section in the same way, the unbaked cables were tested 50 times for

IPolytec Scanning Laser Vibrometer PSV-400 Hardware Manual, .pdf file provided by Polytec, Inc. via email. each cable, 10 runs for each of the 5 sections, measured at the driving point. In addition, scans of each cable, in which the response of the cable was measured at discrete points along the entire length of the cable (including both buffer zones and the test zone), were taken to identify and visualize the cables' mode shapes and ensure the accurate comparison of modes.

The experimental data from the unbaked cables showed significant variation between cable sections, although each section had repeatable, nearly identical results from run to run. Thus, rather than use all of the sections for comparison, the most well-behaved cables were selected to be baked out and compared, where well-behaved cables showed the least spread among fundamental frequency values and the most similarity between frequency response functions for each trial. Natural frequencies and damping ratios can be evaluated for each peak in the frequency response function, and observing the vibrometer animation of data at the peak frequencies showed the motion for each mode and mode shape. Figure 8 shows the frequency response function from a single run of a $1 \times \overline{7}$ cable with the first and second beam modes identified as well as the interaction modes. The form of the frequency response function was similar for all single-strand cables; there were clear modes for the first and second beam modes, in which the center test section of the cable showed the symmetric mode shapes that would be expected for a vibrating beam. Between the first and second beam modes were interaction modes, in which the beam modes of the buffer sections affected the test section. The thicker cables showed interaction modes that were nearly equal in magnitude to the first beam mode, and laser scans had to be used to conclusively identify the first beam mode. Each of the three wellbehaved sections for each cable type was tested 13 times with the standard run procedure and scanned at least twice along the length of the cable at 58 different points to yield the unbaked cable data.

\section{Bakeout Procedure}

The standard Earth orbiter bakeout process requires pressure on the order of $1 \times 10^{-5}$ torr at $+105 \pm 5 \mathrm{C}$ for $72 \mathrm{~h}$ [5], although this varies depending on the hardware and ultimate destination of the craft. The cables were baked out over $72 \mathrm{~h}$ at a near-constant $105 \mathrm{C}$ temperature and a low pressure of $1.3 \times 10^{5}$ torr. Cables were weighed before and after bakeout to $1 \mathrm{~g}$ resolution and showed negligible mass change. Figure 9a shows the cables racked for bakeout, and Fig. 9b shows the bakeout chamber used. Cables were kept straight for transport and bakeout.

\section{Baked Cable Testing}

The bakedout cables were then tested using the same standard run methods and test configuration. Each section was again scanned along the entire length of the cable to determine if there were differences in mode shapes and to verify that the frequencies being

Table 2 Cable physical measurements

\begin{tabular}{lcccccc}
\hline \hline & $\begin{array}{c}\text { Number } \\
\text { of } \\
\text { Wires }\end{array}$ & $\begin{array}{c}\text { Mass, } \\
\mathrm{kg}\end{array}$ & $\begin{array}{c}\text { Length, } \\
\mathrm{m}\end{array}$ & $\begin{array}{c}\text { Diameter, } \\
\mathrm{m}\end{array}$ & $\begin{array}{c}\text { Lay } \\
\text { length, } \\
\mathrm{m}\end{array}$ & $\begin{array}{c}\text { Lay } \\
\text { angle, } \\
\text { deg }\end{array}$ \\
\hline $1 \times 7$ & 7 & 0.0725 & 0.769 & 0.0075 & 0.0688 & 19.02 \\
$1 \times 19$ & 19 & 0.1905 & 0.778 & 0.0127 & 0.1325 & 16.85 \\
$1 \times 48$ & 48 & 0.4445 & 0.774 & 0.0203 & 0.2118 & 16.79 \\
$7 \times 7$ & 49 & 0.4944 & 0.775 & 0.0217 & 0.2128 & 17.75 \\
\hline \hline
\end{tabular}




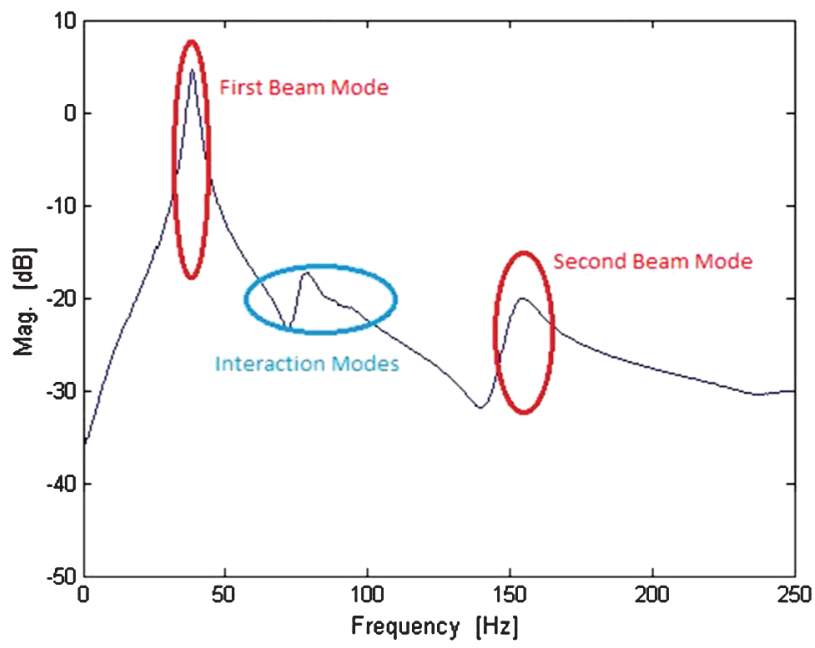

Fig. 8 Anatomy of a single-strand cable mobility frequency response function.

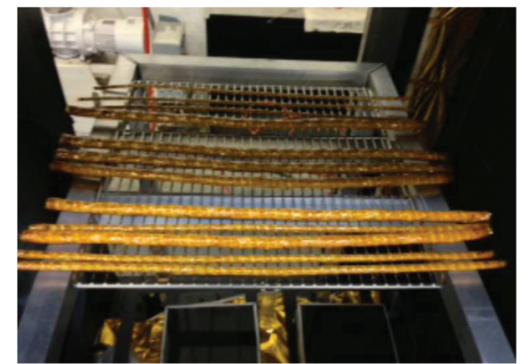

a)

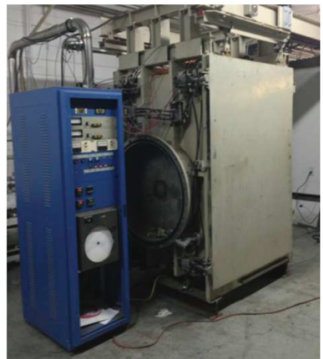

b)
Fig. 9 Cable undergoing the bakeout process.

compared were indeed referencing the same mode. Single-point measurements were taken at the driving point to find the first and second frequency value for each run for each section. Each of the three baked sections for the four different cable types were tested between 14 and 18 times, with scans run on each of the baked cable sections two or three times. All test procedures and methods were kept exactly the same, so the only change was the bakeout treatment. Based on the comparison between the data from the baked cables and the previously collected data from the same cables before bakeout, the bakeout procedure does have an effect on cable dynamics, as revealed in the next section.

\section{Results}

Data were analyzed using laser vibrometer software and ME Scope. Frequency response functions and mode shape visualizations were

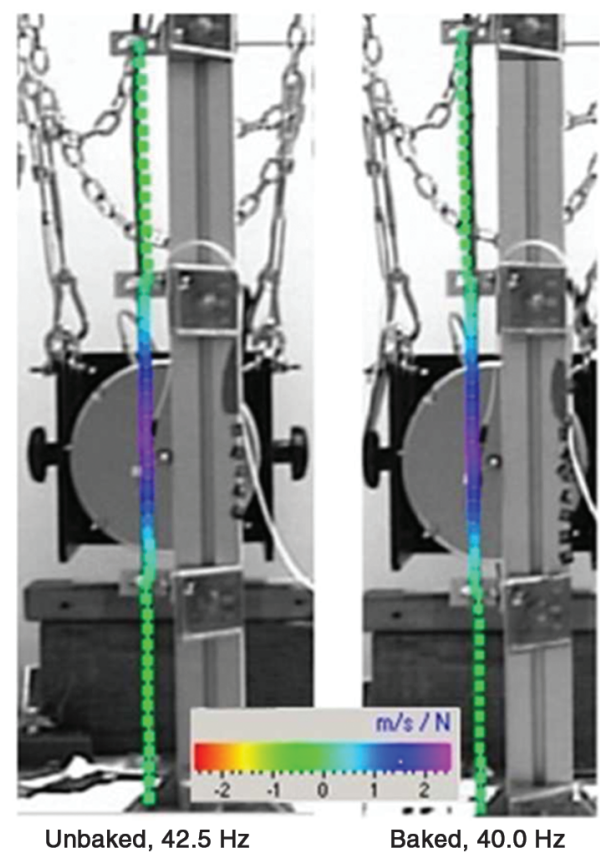

Fig. 11 First beam mode comparison between the unbaked and baked cables, $1 \times 7$.

determined from the raw vibrometer data, and damping values were determined using ME Scope software. ME Scope was also used to verify the frequency values extracted from the vibrometer software. The frequency response functions indicated the natural frequencies, and mode shape identification ensured valid comparison between the same modes; although the first and second modes were very clear for the $1 \times 7$ and $1 \times 19$ cables, there was some ambiguity in the frequency response functions for the larger cables due to the similarity in magnitude between the first mode and interaction modes, so comparison of the mode shapes through scan inspection ensured that the natural frequencies were being compared appropriately. The singlestrand cables consisted of a single wire surrounded by layer wires in configurations of 7, 19, or 48 wires. They all showed a clear first and second frequency separated by interaction modes. Comparison of individual sections and individual section data can be found in the Appendix; frequency responses for each section showed less variation overall than for each type of cable as a whole. It appears that even very carefully machine-manufactured cables still show differences from section to section, although the differences were much less than for hand-built cables tested previously.

\section{A. Single-Strand $1 \times 7$ Cable}

Figure 10 shows the comparison for all of the $1 \times 7$ cable sections in which red dashed lines are the unbaked cable responses and blue

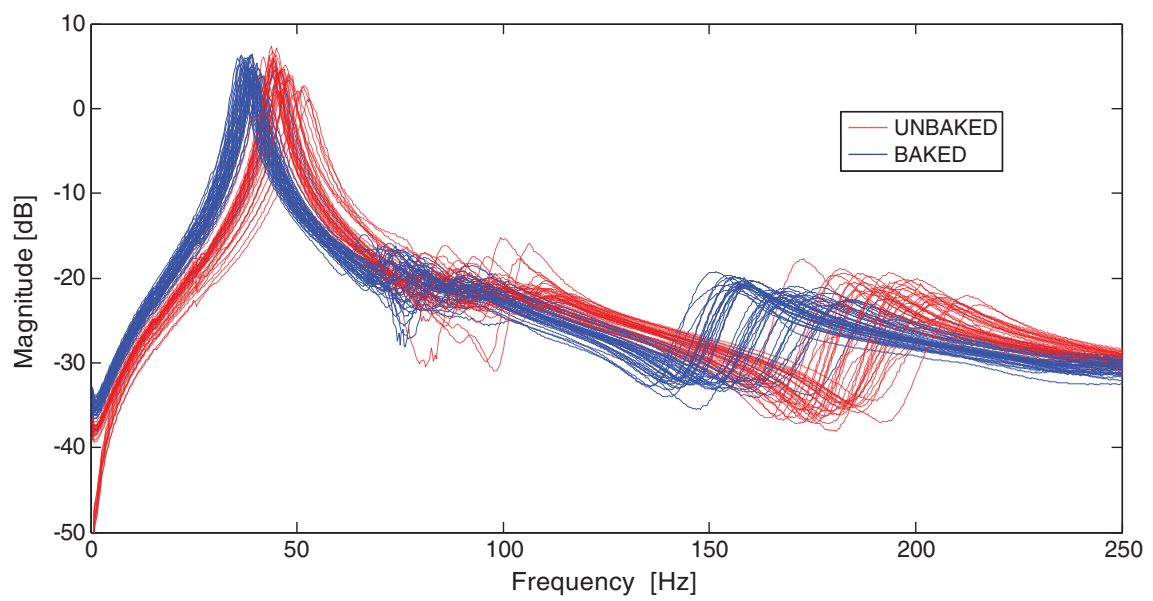

Fig. 10 Comparison of cables before and after bakeout, showing a decrease in natural frequencies for the $1 \times 7$ cable. 


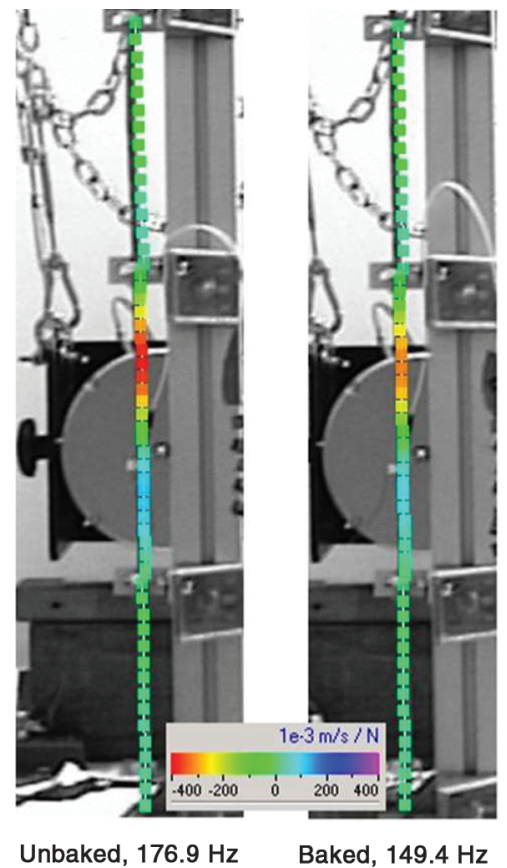

Fig. 12 Second beam mode comparison between unbaked and baked cable, $1 \times 7$.

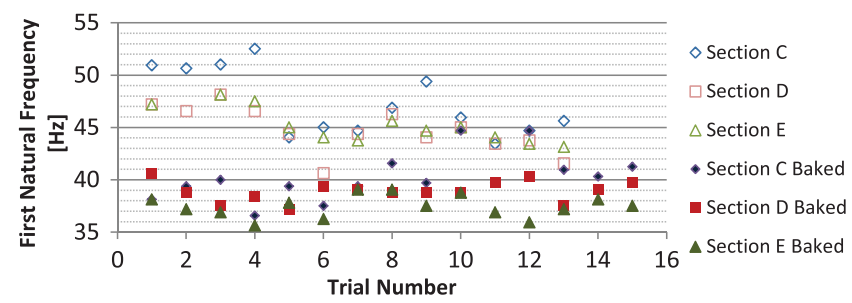

Fig. 13 First natural frequencies for $1 \times 7$ cable sections, showing a lower frequency trend of baked cables.

solid lines show the cable responses after bakeout. For every section of the $1 \times 7$ cable, the first and second natural frequencies shifted to the left beyond the variation between the cable sections. The first and second beam modes are much more consistent in frequency and amplitude than the interaction modes. This is likely due to interaction modes being very dependent on the constriction of the cable at the attachment points; although cable tie tension was kept constant, the random way that the individual wires were compressed as the tie was tightened for each installation of the cable in the test fixture may have contributed to the interaction mode variation.

To show where the first and second modes occur, the cable was scanned, and mode shapes were identified. The cable showed clear

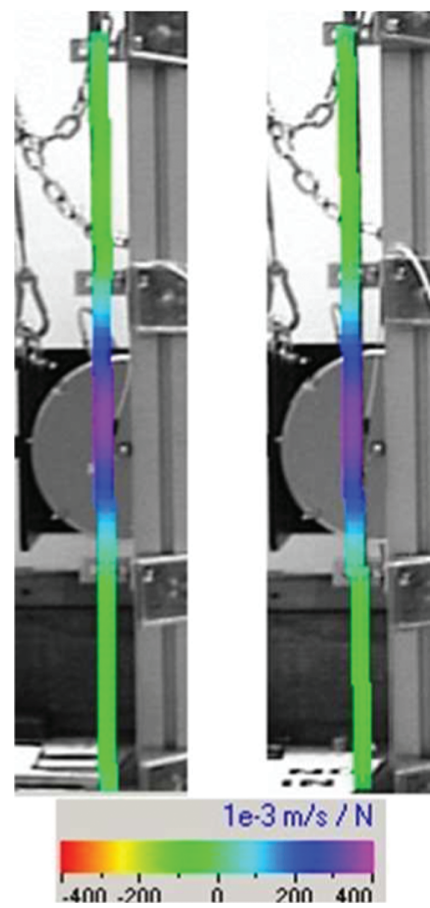

Fig. 15 First mode comparison for $1 \times 19$ cables, showing a difference of $15.3 \%$.

beam modes, which were used to identify the modes of the test section. The unbaked cable first frequency occurred around $45 \mathrm{~Hz}$, and the second frequency occurred around $180 \mathrm{~Hz}$. The modes that occurred between 50 and $100 \mathrm{~Hz}$ were interaction modes, in which the buffer zones showed their first beam modes. This is valuable information since cables are usually attached in multiple places and would show these interaction modes in practice as well. The first mode can be differentiated from the interaction modes by the lack of activity shown in the buffer zones at this point. Interaction modes are characterized by displacements in the buffer zones that are similar in magnitude to the center test section. Figure 11 shows the mode shapes for the $1 \times 7$ cable from the laser vibrometer software; the left side of the image is an unbaked cable, in which the first beam mode occurred at $42.5 \mathrm{~Hz}$, and the image on the right side is the same cable section after bakeout, showing the same first beam mode at $40.0 \mathrm{~Hz}$, a difference of nearly $6 \%$. The mode shapes were nearly identical in magnitude but occurred at different frequencies. Figure 12 shows the comparison between mode shapes for the second frequency; here, the unbaked cable resonated at $176.9 \mathrm{~Hz}$ and the baked cable at $149.4 \mathrm{~Hz}$, a difference of over $15 \%$. Here, however, the magnitude of the baked cable was somewhat decreased, indicating higher damping due to bakeout changes.

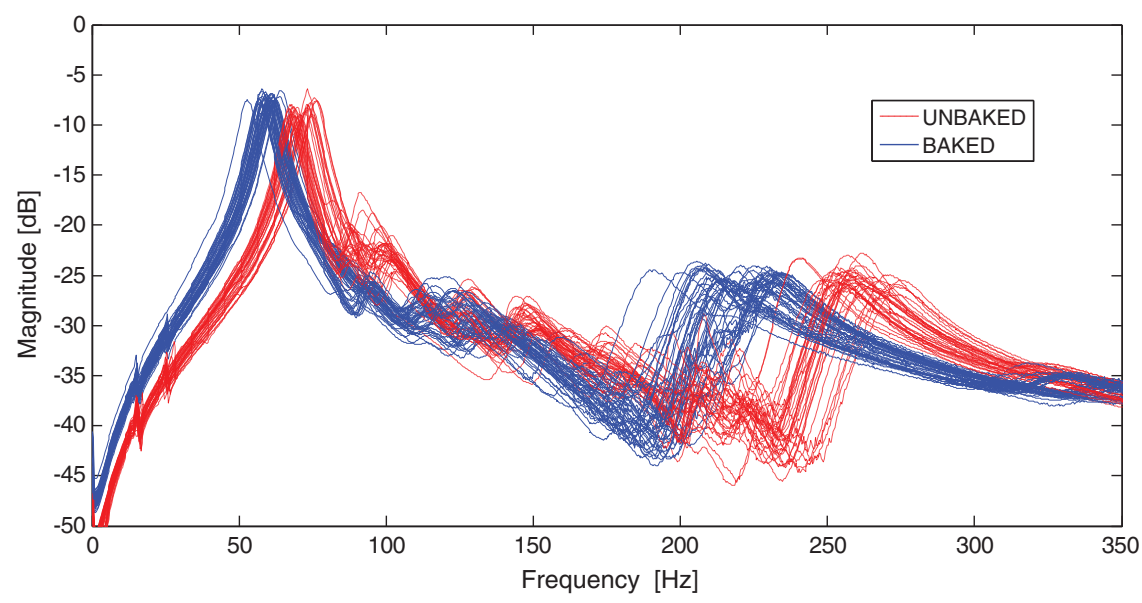

Fig. 14 Comparison of unbaked and baked cables, showing a decrease in natural frequencies for the $1 \times 19$ cable. 


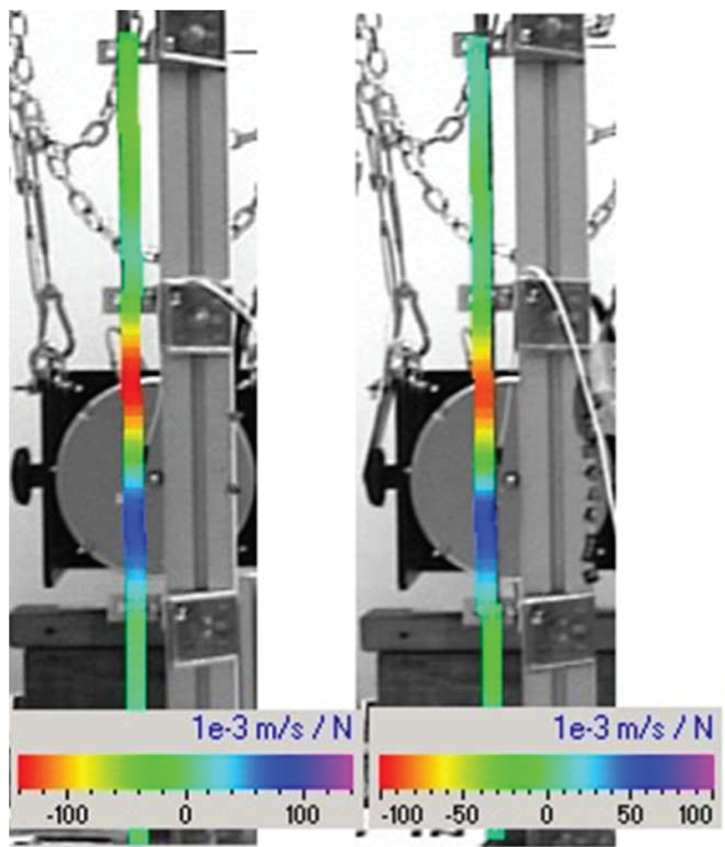

Fig. 16 Second mode comparison for $1 \times 19$ cables, showing a difference of $15.1 \%$.

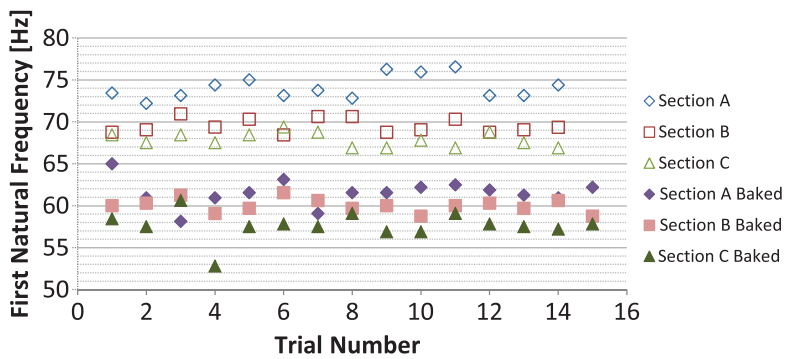

Fig. 17 First natural frequencies for $1 \times 19$ cable sections, showing a lower frequencies of baked cables.

Figure 13 shows a graph of the first natural frequency value taken from single-point data for all of the unbaked and baked trials for the $1 \times 7$ cables, again showing a clear decrease in frequency for the baked cables. The $1 \times 7$ section $\mathrm{C}$ cable was the only cable that showed a downward trend in frequency for the first few unbaked trials. This is likely due to the bedding in effect, in which continued vibration of the cable changes the frictional force between the wires and thus decreases the natural frequency. The term bedding in is used throughout Raoof's research on spiral strands and differentiates an
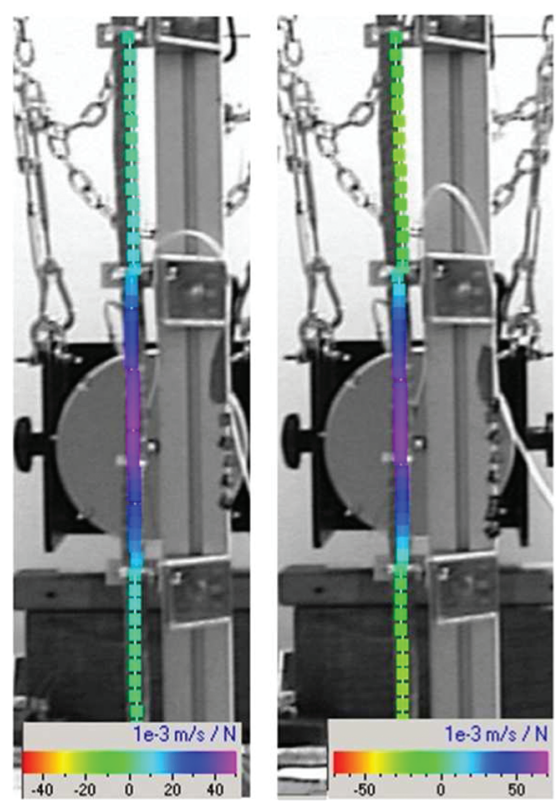

Unbaked, $117.2 \mathrm{~Hz}$

Baked, $107.8 \mathrm{~Hz}$

Fig. 19 First mode comparison for $1 \times 48$ cables.

old cable that has experienced vibration from a newly manufactured cable [18]. After the first five trials, it appears that the cable is completely bedded in. It should be noted that efforts were made to vibrate all cables by the same amount and same duration to eliminate any differences due to bedding in. It should also be noted that section $\mathrm{C}$ of the $1 \times 7$ set was the most poorly behaved of all of the cable samples, which is observed in its unusually high frequency values at trials 10 and 12 of the baked cable testing. Overall though, it still follows the general trend shown clearly by $1 \times 7$ sections $\mathrm{D}$ and $\mathrm{E}$, which show an average decrease in first natural frequency of 12.7 and $17.2 \%$, respectively.

\section{B. Single-Strand $1 \times 19$ Cable}

Frequency response functions, mode shapes, and natural frequencies were collected for the $1 \times 19$ cables as well. The frequency response functions for all baked and unbaked $1 \times 19$ trials are shown in Figure 14, again showing a decrease in effective stiffness for both first and second beam mode frequencies.

Figures 15 and 16 show the matching mode shapes for the first and second beam modes with a $15 \%$ reduction in the frequency of the baked cable shown on the right side of each figure. Figure 17 shows the trend in the first natural frequency as compared between the unbaked and baked cable trials from the single-point data of the $1 \times 19$ trials. The frequency difference here ranged from 13.2 to

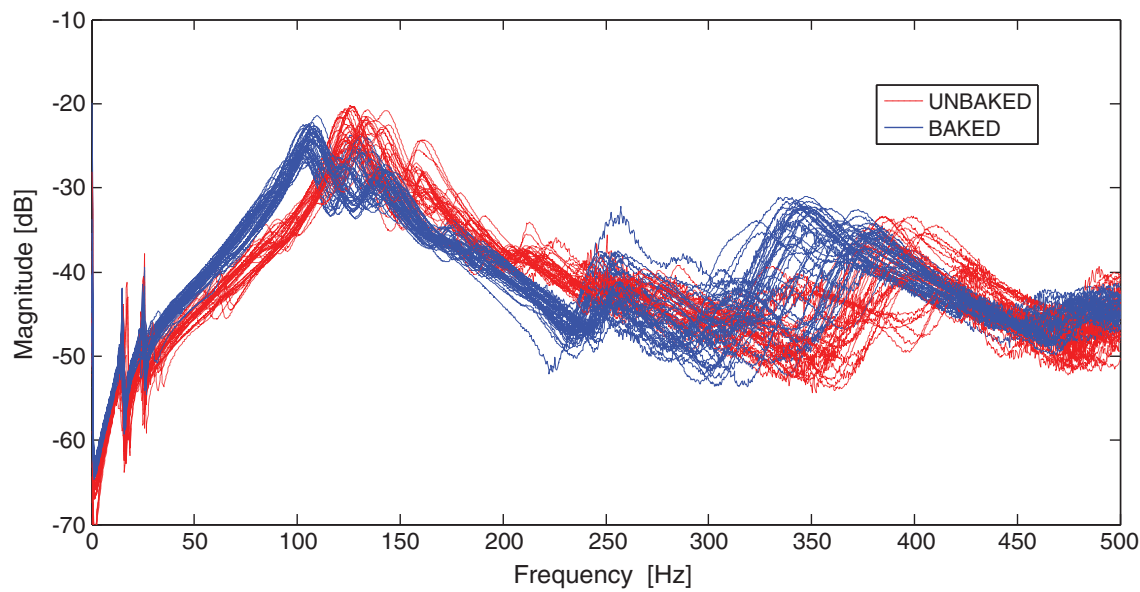

Fig. 18 Comparison of unbaked and baked cables, showing a decrease in natural frequencies for the $1 \times 48$ cable. 


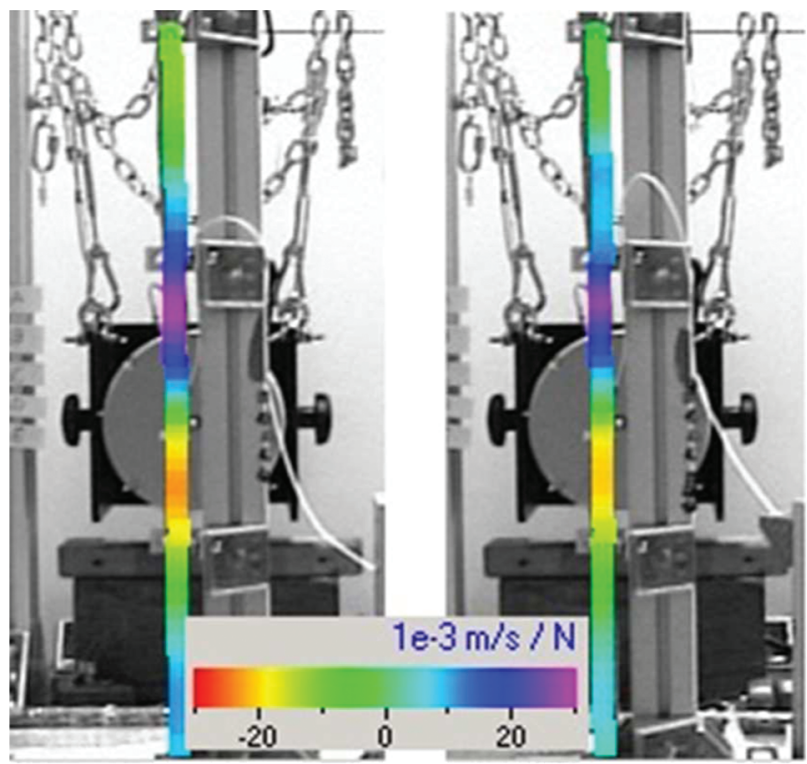

Unbaked, $389.1 \mathrm{~Hz}$

Baked, $348.1 \mathrm{~Hz}$

Fig. 20 Second mode comparison for $1 \times 48$ cables.

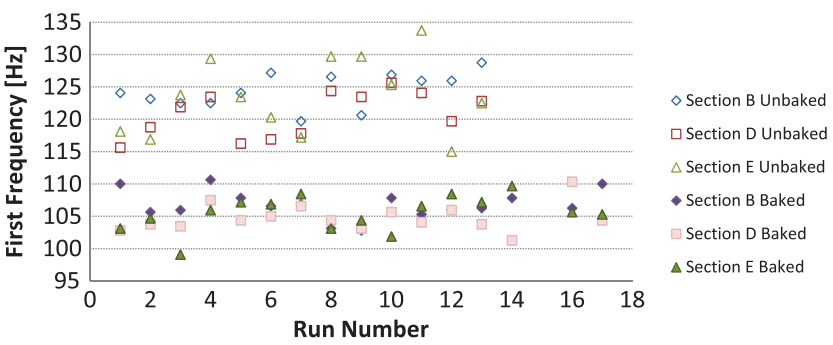

Fig. 21 First natural frequencies for $1 \times 48$ cable sections, showing lower frequencies of baked cables.

$16.2 \%$, and in no trial was the baked cable frequency ever higher than the unbaked cable frequency. This cable, being the medium-sized cable that the standard run was designed for, showed excellent repeatability and a clear trend through all trials. No bedding in effect was observed.

\section{Single-Strand $1 \times 48$ Cable}

The much stiffer cable showed frequency response functions with modes that could not be as easily identified by inspection alone. This is where the identification of the matching mode shapes became necessary since there was ambiguity in the peaks of the frequency response functions. Figure $\underline{18}$ shows the FRFs of all of the $1 \times 48$
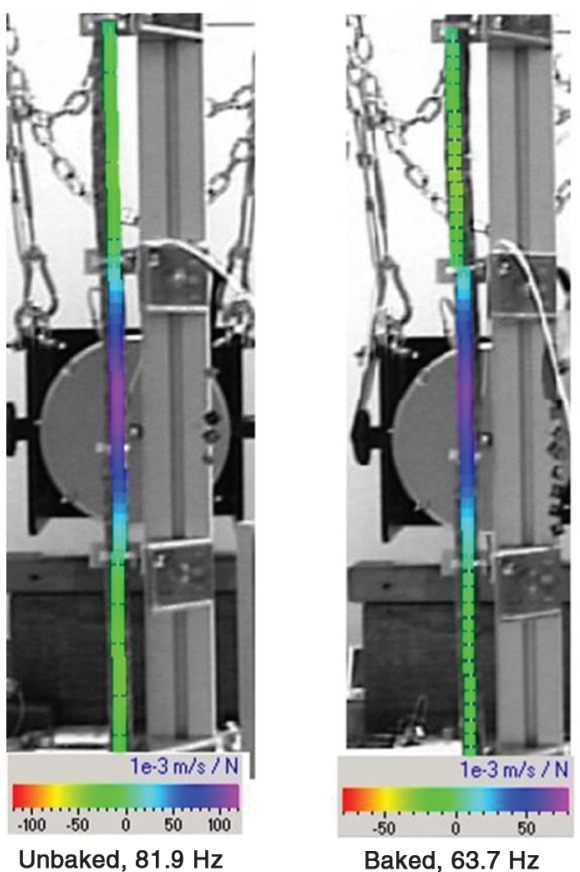

Fig. 23 First mode comparison for $7 \times 7$ cables.

trials, where the first beam mode of the cable test section is no longer as clearly defined due to the close proximity of the interaction modes (which occurs because this cable is much stiffer and larger and experiences less constriction at the pinned connections between the buffer zones and test section). Figures 19 and 20 show the $1 \times 48$ cable's first and second mode shapes, respectively. The unbaked cable resonated at $117.2 \mathrm{~Hz}$ for the first beam mode and $389.1 \mathrm{~Hz}$ for the second beam mode, while the same cable after bakeout resonated at 107.8 and $348.1 \mathrm{~Hz}$, differences of 8 and $10.5 \%$ for the first and second modes. Figure 21 shows a graph of the first peak frequency values from single-point data. As with the other single-strand cables, every baked trial showed lower frequency values than every unbaked trial.

\section{Multistrand $7 \times 7$ Cable}

The $7 \times 7$ cable was made to compare to the $1 \times 48$ cable; although both cables have about the same number of wires, the multistrand cable is significantly more flexible since it is made up of strands instead of individual wires. The data collected were consistent with the theory; the multistrand cable was less stiff with lower first and second natural frequencies than the single-strand cable of the same size.

The proximity of the interaction modes became an even greater issue for the $7 \times 7$ cable, and inspection of the mode shapes was

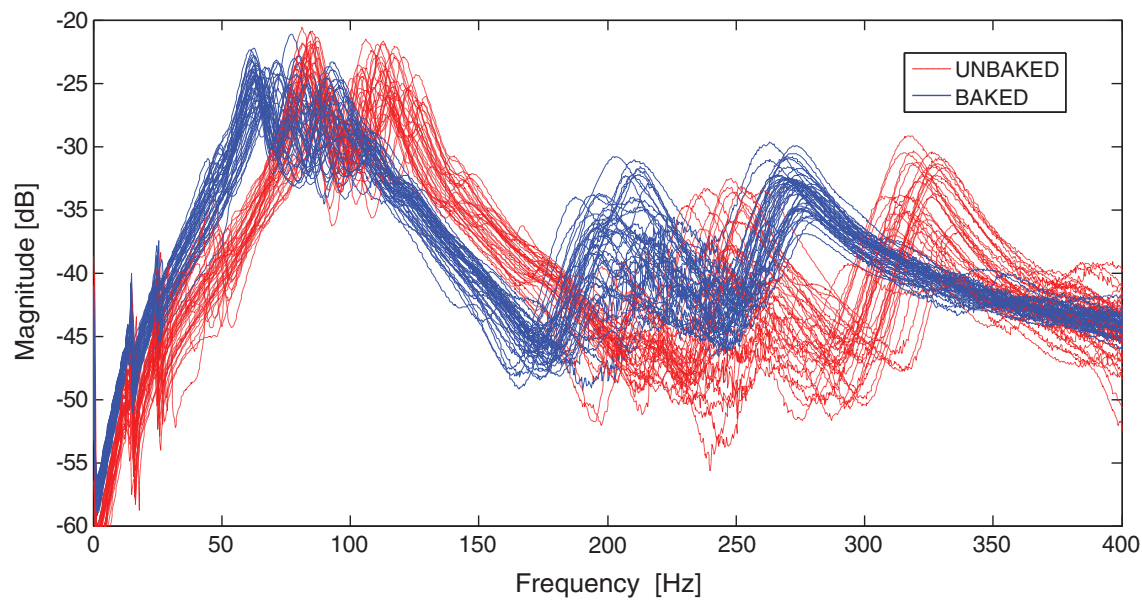

Fig. 22 Comparison of unbaked and baked cables, showing a decrease in natural frequencies for the $7 \times 7$ cable. 


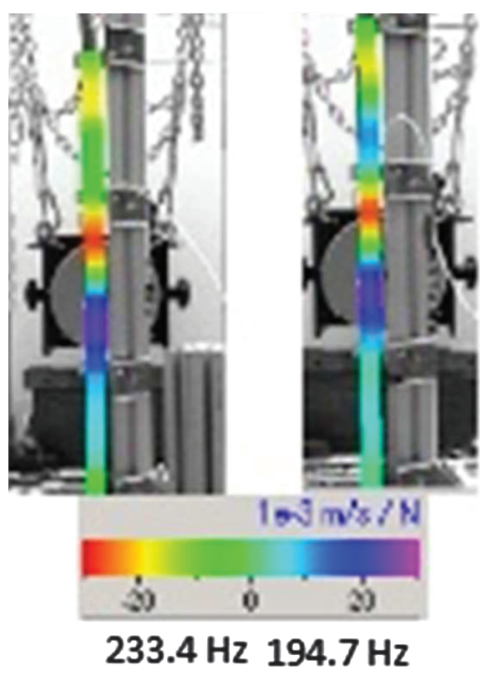

Fig. 24 Second mode comparison for $7 \times 7$ cables.

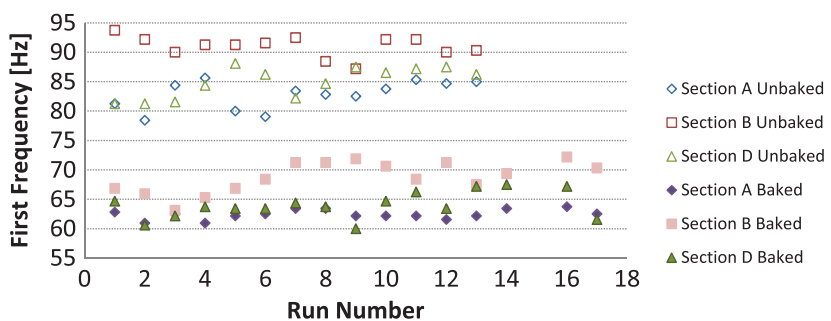

Fig. 25 First natural frequencies for $7 \times 7$ cable sections, showing lower frequencies of baked cables.

necessary to determine which frequencies corresponded to the first and second beam modes of the cable test section. Figure 22 shows the FRFs for all $7 \times 7$ cable trials, still showing a left shift for the baked cables. The more flexible multistrand configuration did show a lower natural frequency than the $1 \times 48$ cable with similar wire count as expected. Although the interaction modes appeared larger and in different locations than for the single-strand cables, the overall pattern of frequency decrease still occurred.

It is not necessarily the highest peak in the FRF that corresponds to the first frequency, which indicates that the interaction modes may be just as important in these larger cables to consider when determining maximum amplitude. Figures 23 and 24 show the scan images for the first and second modes of the $\overline{7} \times 7$ cable. The first frequency was reduced from 81.9 to $63.7 \mathrm{~Hz}$, and the second frequency was reduced from 234 to $194 \mathrm{~Hz}$, differences of almost 23 and 18\%, respectively. Figure 25 shows another clear separation between baked and unbaked cable frequencies, with all baked frequencies for the $7 \times 7$ cable significantly lower than the unbaked frequencies.

\section{E. Overall Observations and Results}

Data were taken in the form of multiple single-point runs and scans of the entire cable. Results from the single-point values for each of the three test sections for each of the four types of cable were averaged. Overall averages made up of the section averages were then recorded for each type of cable and are presented in Table 3. These averages were based on 39-54 runs per cable type, removed and remounted in the test section each time. The results from the singlepoint data agreed well with averages taken from the laser scans and those evaluated using ME Scope. The change in frequencies was consistent; all unbaked first frequencies for single-strand cables decreased between 14 and $15 \%$ after bakeout on average. However, the multistrand cable showed a more significant reduction in frequency at both the first and second beam modes. All values presented in Table $\underline{3}$ are averages from measurements taken at the driving point.

The coefficient of variation was calculated for the baked trials, the unbaked trials, and then for all of the trials together for each cable. The coefficient of variation ranged from 0.015 to 0.06 for unbaked trials, from 0.02 to 0.05 for baked trials, and from 0.05 to 0.2 for combined unbaked and baked trials. The coefficient of variation for the combined trials for each frequency for each cable was larger than for the baked or unbaked trials in every case and was almost always larger by a factor of 2-4. This shows that the frequency change exhibited by the bakedout cables was greater than what could be expected due to experimental variation. The list of coefficients of variation for each section and for each type of cable overall can be found in the Appendix. More data are available from scans of the entire cable, but as the frequencies were within the distribution of the single-point data and agreed with the overall results, the additional scans were considered superfluous.

Damping values were also investigated by using ME Scope to determine the damping percentage at the first mode. While the magnitude of the frequency response functions did not indicate a clear trend for damping behavior after bakeout, the percent damping calculated using ME Scope showed an increase in damping percentage for all cables after bakeout. Table 4 presents the average damping percentage for the first frequency for each cable. This information is based on cable scan data.

This damping ratio data agree very well with previously published data of 3-6\% for unbaked cables of similar sizes [3], but bakeout treatment pushes the larger cables outside of this range, providing further evidence that bakeout effects should be taken into account for modeling and design purposes.

There are a few likely mechanisms to explain the cable stiffness softening effect exhibited. First, it was observed that the Tefzel insulation coating had shrunk down around the wire after bakeout,

Table 4 Percent difference in first frequency average damping percentage for each cable

\begin{tabular}{lcc}
\hline \hline & \multicolumn{2}{c}{ First frequency } \\
\cline { 2 - 3 } Cable & $\begin{array}{c}\text { Average Damping, } \\
\text { Unbaked, \% }\end{array}$ & $\begin{array}{c}\text { Average Damping, } \\
\text { Baked, \% }\end{array}$ \\
\hline $1 \times 7$ & 3.40 & 3.72 \\
$1 \times 19$ & 4.96 & 5.74 \\
$1 \times 48$ & 3.65 & 7.05 \\
$7 \times 7$ & 4.83 & 9.07 \\
\hline \hline
\end{tabular}

Table 3 First and second frequencies for baked and unbaked cases for four different cable configurations

\begin{tabular}{lccccccc}
\hline \hline & \multicolumn{3}{c}{ Average first frequency } & & \multicolumn{3}{c}{ Average second frequency } \\
\cline { 2 - 3 } \cline { 6 - 8 } Cable & Unbaked, $\mathrm{Hz}$ & Baked, $\mathrm{Hz}$ & Change, $\%$ & & Unbaked, $\mathrm{Hz}$ & Baked, $\mathrm{Hz}$ & Change, $\%$ \\
\hline $1 \times 7$ & 46.1 & 39.3 & 14.8 & & 195.6 & 166.8 & 14.7 \\
$1 \times 19$ & 70.5 & 59.9 & 14.9 & & 257.9 & 220.5 & 14.5 \\
$1 \times 48$ & 122.9 & 105.7 & 14.0 & & 394.5 & 360.4 & 8.6 \\
$7 \times 7$ & 86.3 & 65.1 & 24.6 & & 247.9 & 206.0 & 16.9 \\
\hline \hline
\end{tabular}


indicating that the Tefzel coating may have shrunk overall, binding the individual conductors more snugly but providing more interstitial space in between the individual wires. The increase in space may lead to a decrease in the radial pressure holding the wires together, thus making the individual wires act more like a flexible set of wires and less like a stiff solid beam. Another hypothesis relates to the outgassing of plasticizers in cable insulation, but since plasticizers are not present in the Tefzel insulation used for these wires, that is unlikely to be a mechanism that contributes to the changes observed. The Kapton overwrap may also experience changes due to the bakeout treatment; the Kapton becomes more brittle after heat treatment, which may lead to the perception that the cable is stiffer even though its dynamic stiffness has decreased. It was observed that when holding baked and unbaked cables out as cantilevered beams the baked cable showed a larger amount of end displacement, providing further verification that the bakedout cables become less stiff after bakeout.

For the frequency reduction exhibited in the bakedout cables, the theoretical model in Sec. III requires a reduction in the bending stiffness value of about an order of magnitude, with the bakedout cables having a bending stiffness of about $10 \%$ of the unbaked cable when connection stiffness is on the order of $5 \times 10^{4} \mathrm{~N} / \mathrm{m}$. This is indeed a sizeable change in the bending stiffness value that must be incorporated into cabled structure models if the other model inputs (such as connection stiffness, density, and area) remain the same.

\section{Conclusions}

Cable dynamic response was tested before and after the cables experienced heat and vacuum treatment known as bakeout. The cable response after bakeout showed clear and significant differences when compared to the frequency response before bakeout. For the cables tested, a low-Earth-orbit bakeout reduced the natural frequencies of single-strand cables by about $14 \%$, reduced multistrand cable frequencies by at least $16 \%$, and increased damping in all cable types. The reduction in natural frequency values indicated that the cable became less stiff after bakeout, and amplitude response was diminished due to the increase in cable damping. Current theoretical bending stiffness calculations are unable to capture the effects of bakeout, so to predict cable bending stiffness after bakeout, a bakeout correction factor should be determined, or cables must be tested postbakeout to determine how the modulus of elasticity of the wires, cable inertia, or interwire friction has changed. Thus, the authors recommend that the softening and damping effects due to bakeout be kept in mind when using cable stiffness or frequency values for spaceflight applications that will require bakeout of flight cables.

\section{Appendix A: Individual Section Tables and Graphs of Cable Comparisons by $1 \times 7$ Cable Section Averages}

See Tables $\underline{A} 1-$ A8 and Figs. A1- $\underline{\text { A4 }}$.

Table A1 $1 \times 7$ cable section averages

\begin{tabular}{ccccccc}
\hline \hline & $\begin{array}{c}\text { Unbaked first mode } \\
\text { average frequency, } \mathrm{Hz}\end{array}$ & $\begin{array}{c}\text { Baked first mode } \\
\text { average frequency, } \mathrm{Hz}\end{array}$ & $\begin{array}{c}\text { Change, } \% \\
\text { Cnsaked second mode } \\
\text { average frequency, } \mathrm{Hz}\end{array}$ & $\begin{array}{c}\text { Baked second mode } \\
\text { average frequency, Hz }\end{array}$ & Change, $\%$ \\
\hline $\mathrm{C}$ & 47.64 & 40.78 & 14.4 & 204.40 & 177.48 & 13.2 \\
$\mathrm{D}$ & 45.14 & 39.41 & 12.7 & 187.96 & 157.71 & 16.1 \\
$\mathrm{E}$ & 45.53 & 37.68 & 17.2 & 194.40 & 165.21 & 15.0 \\
Overall & 46.11 & 39.29 & 14.8 & 195.58 & 166.80 & 14.7 \\
\hline \hline
\end{tabular}

Table A2 $1 \times 7$ cable coefficients of variation

\begin{tabular}{ccccccc}
\hline \hline $1 \times 7$ & $\begin{array}{c}\text { First mode } \\
\text { unbaked }\end{array}$ & $\begin{array}{c}\text { First } \\
\text { mode baked }\end{array}$ & $\begin{array}{c}\text { First mode } \\
\text { all trials }\end{array}$ & $\begin{array}{c}\text { Second } \\
\text { mode unbaked }\end{array}$ & $\begin{array}{c}\text { Second } \\
\text { mode baked }\end{array}$ & $\begin{array}{c}\text { Second mode } \\
\text { all trials }\end{array}$ \\
\hline $\mathrm{C}$ & 0.072 & 0.039 & 0.110 & 0.039 & 0.036 & 0.100 \\
$\mathrm{D}$ & 0.061 & 0.023 & 0.096 & 0.036 & 0.017 & 0.124 \\
$\mathrm{E}$ & 0.043 & 0.035 & 0.133 & 0.041 & 0.043 & 0.115 \\
Overall & 0.059 & 0.047 & 0.113 & 0.038 & 0.035 & 0.112 \\
\hline \hline
\end{tabular}

Comparison of Unbaked and Baked Cables, Section C of 1 by 7

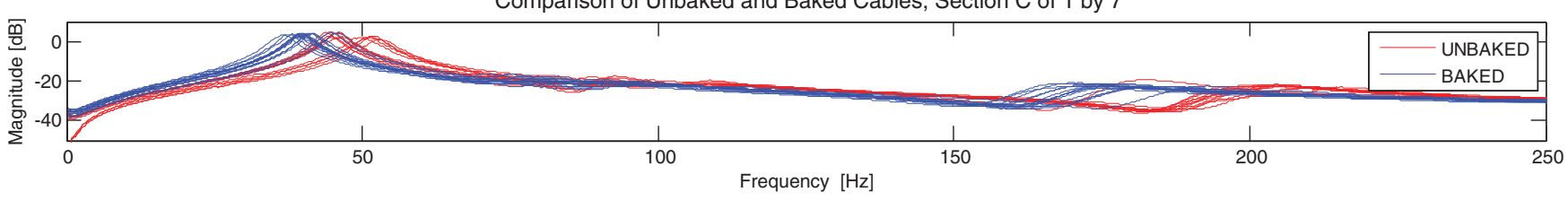

Comparison of Unbaked and Baked Cables, Section D of 1 by 7

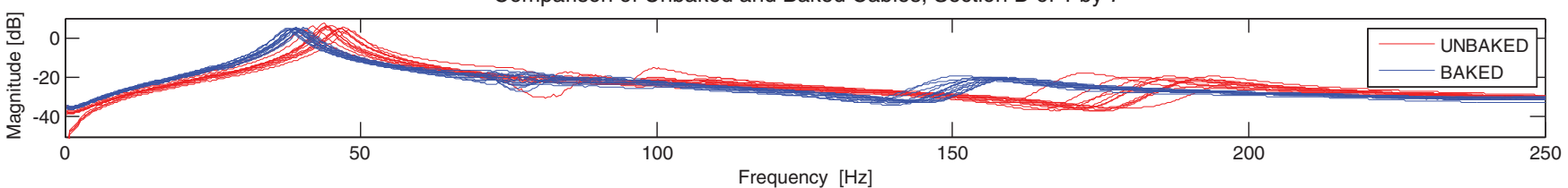

Comparison of Unbaked and Baked Cables, Section E of 1 by 7

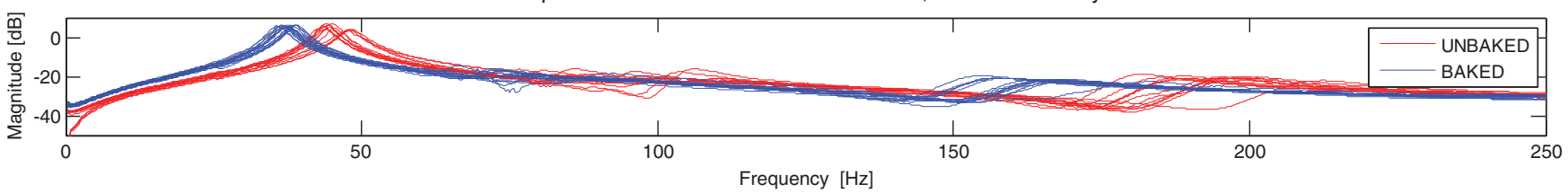

Fig. A1 Effect of bakeout treatment on frequency response of each test section of $1 \times 7$ cable. 
Table A3 $1 \times 19$ cable section averages

\begin{tabular}{|c|c|c|c|c|c|c|}
\hline $1 \times 19$ section & $\begin{array}{l}\text { Unbaked first mode } \\
\text { average frequency, } \mathrm{Hz}\end{array}$ & $\begin{array}{l}\text { Baked first mode average } \\
\text { frequency, } \mathrm{Hz}\end{array}$ & Change, $\%$ & $\begin{array}{l}\text { Unbaked second mode } \\
\text { average frequency, } \mathrm{Hz}\end{array}$ & $\begin{array}{l}\text { Baked second mode average } \\
\text { frequency, } \mathrm{Hz}\end{array}$ & Change, $\%$ \\
\hline $\mathrm{A}$ & 73.96 & 61.95 & 16.2 & 265.06 & 230.53 & 13.0 \\
\hline B & 69.57 & 60.35 & 13.2 & 255.46 & 223.24 & 12.6 \\
\hline $\mathrm{C}$ & 67.84 & 57.54 & 15.2 & 253.27 & 207.81 & 17.9 \\
\hline Overall & 70.45 & 59.95 & 14.9 & 257.93 & 220.53 & 14.5 \\
\hline
\end{tabular}

Table A4 $1 \times 19$ cable coefficients of variation

\begin{tabular}{ccccccc}
\hline \hline $\begin{array}{c}\text { First } \\
1 \times 19\end{array}$ & $\begin{array}{c}\text { First } \\
\text { mode unbaked }\end{array}$ & $\begin{array}{c}\text { First mode } \\
\text { all trials }\end{array}$ & $\begin{array}{c}\text { Second } \\
\text { mode unbaked }\end{array}$ & $\begin{array}{c}\text { Second } \\
\text { mode baked }\end{array}$ & $\begin{array}{c}\text { Second mode } \\
\text { all trials }\end{array}$ \\
\hline $\mathrm{A}$ & 0.019 & 0.027 & 0.125 & 0.027 & 0.030 & 0.099 \\
$\mathrm{~B}$ & 0.011 & 0.020 & 0.100 & 0.022 & 0.036 & 0.095 \\
$\mathrm{C}$ & 0.011 & 0.026 & 0.116 & 0.018 & 0.031 & 0.139 \\
Overall & 0.015 & 0.025 & 0.115 & 0.023 & 0.033 & 0.111 \\
\hline \hline
\end{tabular}

Table A5 $1 \times 48$ cable section averages

\begin{tabular}{ccccccr}
\hline \hline \multirow{1}{*}{$\begin{array}{r}\text { Un section } \\
\text { average frequency, } \mathrm{Hz}\end{array}$} & $\begin{array}{c}\text { Baked first mode } \\
\text { Average frequency, } \mathrm{Hz}\end{array}$ & $\begin{array}{c}\text { Unbaked second mode } \\
\text { Change, } \%\end{array}$ & $\begin{array}{c}\text { Baked second mode } \\
\text { average frequency, } \mathrm{Hz} \\
\text { average frequency, } \mathrm{Hz}\end{array}$ & $\mathrm{Change, \%}$ \\
\hline $\mathrm{B}$ & 124.45 & 106.80 & 14.2 & 384.06 & 346.91 & 9.7 \\
$\mathrm{D}$ & 120.82 & 104.77 & 13.3 & 402.96 & 379.48 & 5.8 \\
$\mathrm{E}$ & 123.46 & 105.47 & 14.6 & 396.47 & 354.90 & 10.5 \\
Overall & 122.91 & 105.68 & 14.0 & 394.50 & 360.43 & 8.6 \\
\hline \hline
\end{tabular}

Table A6 $1 \times 48$ cable coefficients of variation

\begin{tabular}{ccccccc}
\hline \hline First & $\begin{array}{c}\text { First } \\
\text { mode unbaked }\end{array}$ & $\begin{array}{c}\text { First mode } \\
\text { mode baked trials }\end{array}$ & $\begin{array}{c}\text { Second } \\
\text { mode unbaked }\end{array}$ & $\begin{array}{c}\text { Second } \\
\text { mode baked }\end{array}$ & $\begin{array}{c}\text { Second mode } \\
\text { all trials }\end{array}$ \\
\hline $\mathrm{B}$ & 0.022 & 0.021 & 0.108 & 0.014 & 0.021 & 0.072 \\
$\mathrm{D}$ & 0.029 & 0.020 & 0.101 & 0.026 & 0.019 & 0.051 \\
$\mathrm{E}$ & 0.048 & 0.026 & 0.111 & 0.021 & 0.049 & 0.078 \\
Overall & 0.034 & 0.023 & 0.107 & 0.032 & 0.033 & 0.065 \\
\hline \hline
\end{tabular}

Table A7 $\quad 7 \times 7$ cable section averages

\begin{tabular}{ccccccc}
\hline \hline \multirow{7}{7}{$\times 7$ section } & $\begin{array}{c}\text { Unbaked first mode } \\
\text { average frequency, } \mathrm{Hz}\end{array}$ & $\begin{array}{c}\text { Baked first mode } \\
\text { average frequency, } \mathrm{Hz}\end{array}$ & $\begin{array}{c}\text { Unbaked second mode } \\
\text { Change, } \%\end{array}$ & $\begin{array}{c}\text { Baked second mode } \\
\text { average frequency, Hz } \\
\text { average frequency, Hz }\end{array}$ & Change, $\%$ \\
\hline A & 82.79 & 62.42 & 24.6 & 244.83 & 212.89 & 13.0 \\
B & 90.99 & 68.79 & 24.4 & 250.63 & 207.23 & 17.3 \\
D & 84.98 & 64.00 & 24.7 & 248.39 & 197.89 & 20.3 \\
Overall & 86.25 & 65.07 & 24.6 & 247.95 & 206.00 & 16.9 \\
\hline \hline
\end{tabular}

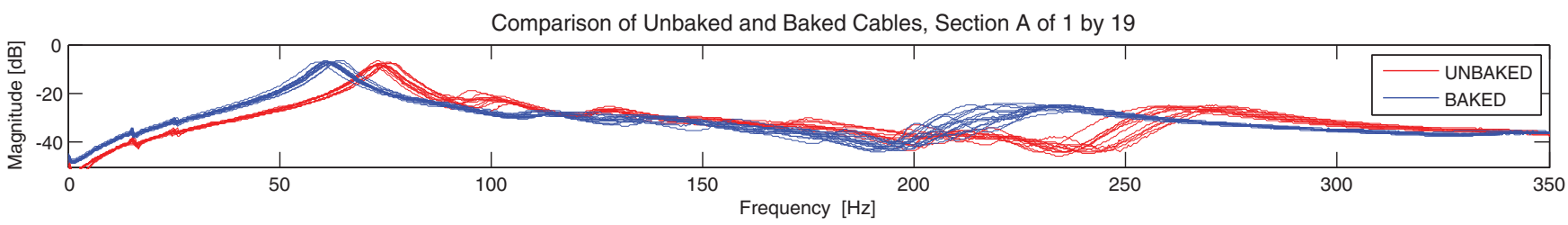

Comparison of Unbaked and Baked Cables, Section B of 1 by 19

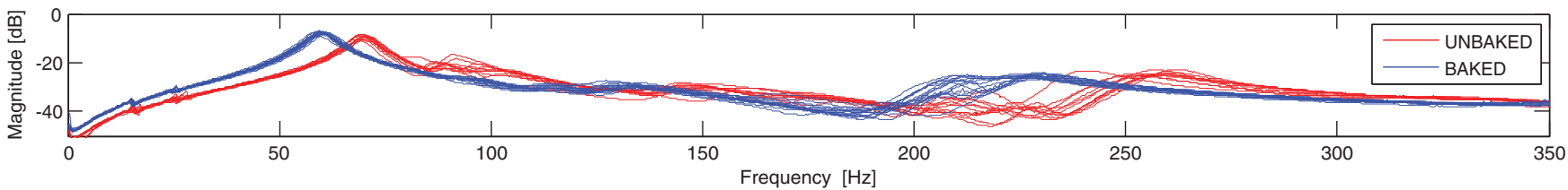

Comparison of Unbaked and Baked Cables, Section C of 1 by 19

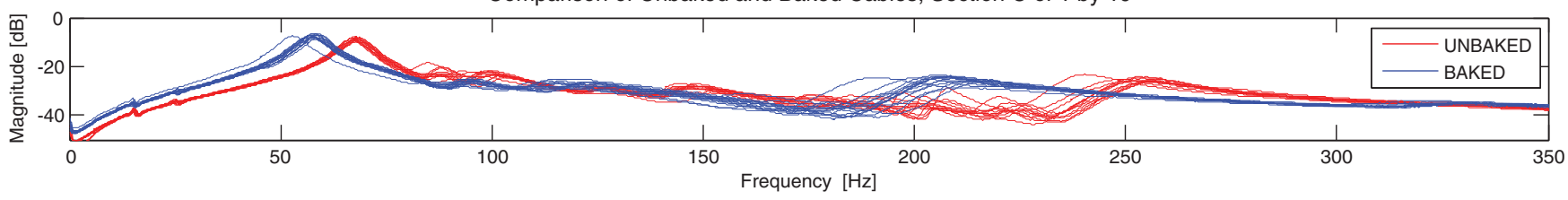

Fig. A2 Effect of bakeout treatment on frequency response of each test section of $1 \times 19$ cable. 
Table A8 $7 \times 7$ cable coefficients of variation

\begin{tabular}{ccccccc}
\hline \hline $7 \times 7$ & First mode unbaked & First mode baked & First mode all trials & Second mode unbaked & Second mode baked & Second mode all trials \\
\hline $\mathrm{A}$ & 0.029 & 0.013 & 0.198 & 0.075 & 0.051 & 0.099 \\
$\mathrm{~B}$ & 0.020 & 0.039 & 0.196 & 0.014 & 0.040 & 0.134 \\
$\mathrm{D}$ & 0.031 & 0.035 & 0.199 & 0.074 & 0.046 & 0.160 \\
Overall & 0.026 & 0.032 & 0.198 & 0.059 & 0.047 & 0.131 \\
\hline \hline
\end{tabular}

Comparison of Unbaked and Baked Cables, Section B of 1 by 48

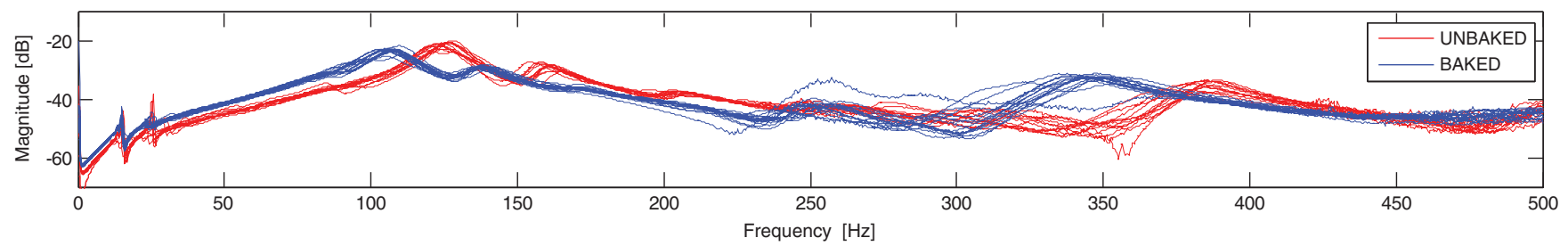

Comparison of Unbaked and Baked Cables, Section D of 1 by 48

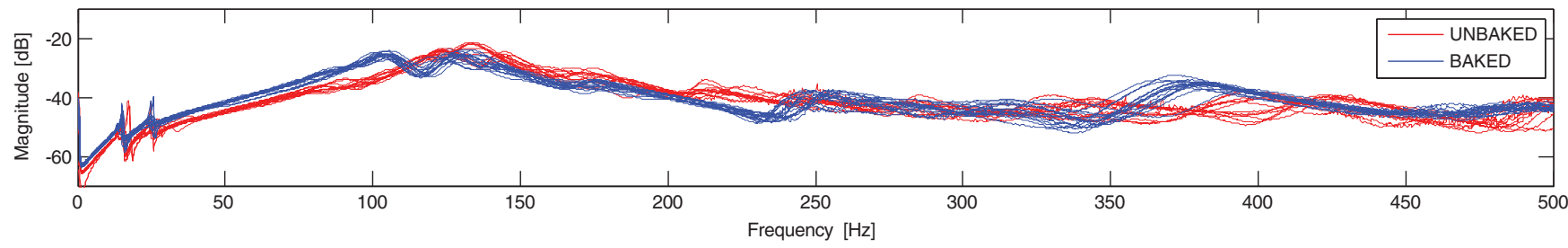

Comparison of Unbaked and Baked Cables, Section E of 1 by 48

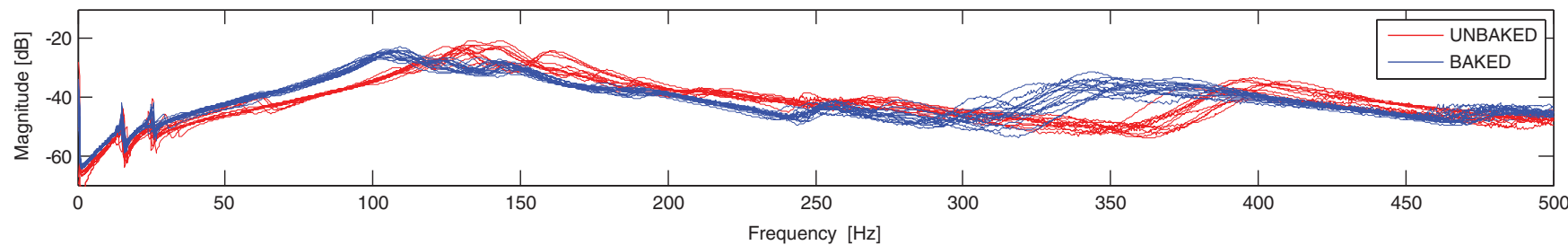

Fig. A3 Effect of bakeout treatment on frequency response of each test section of $1 \times 48$ cable.

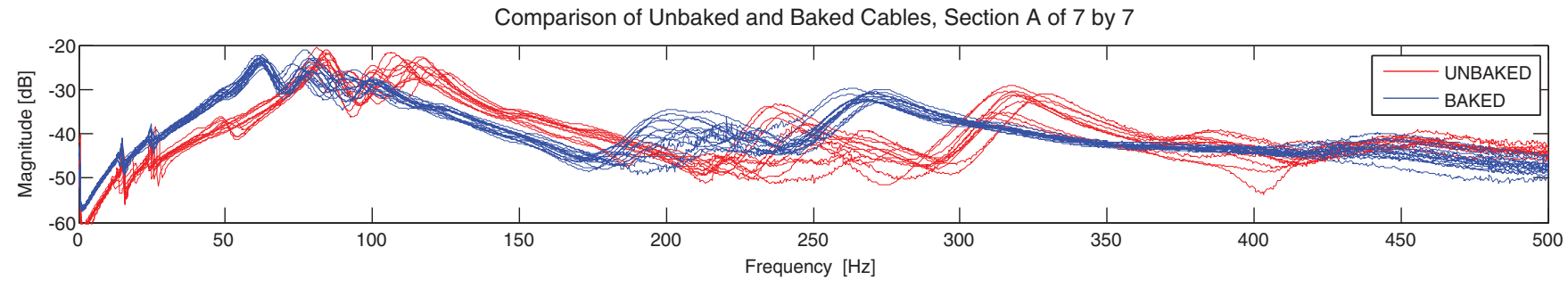

Comparison of Unbaked and Baked Cables, Section B of 7 by 7

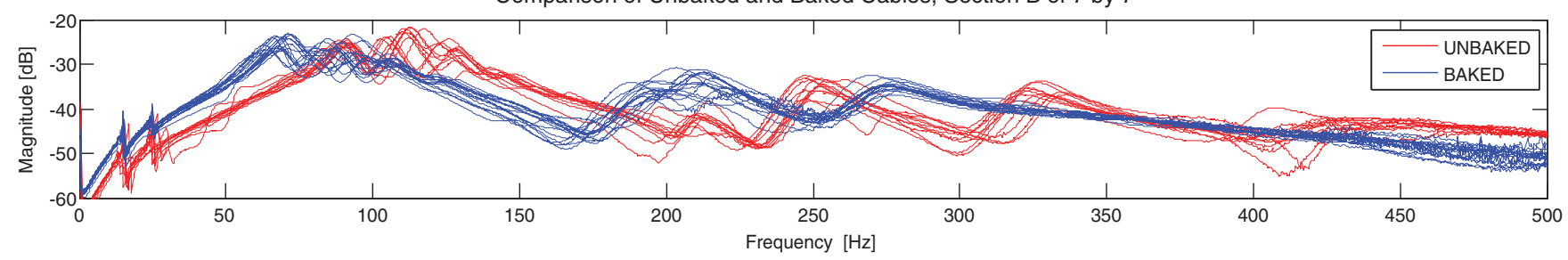

Comparison of Unbaked and Baked Cables, Section D of 7 by 7

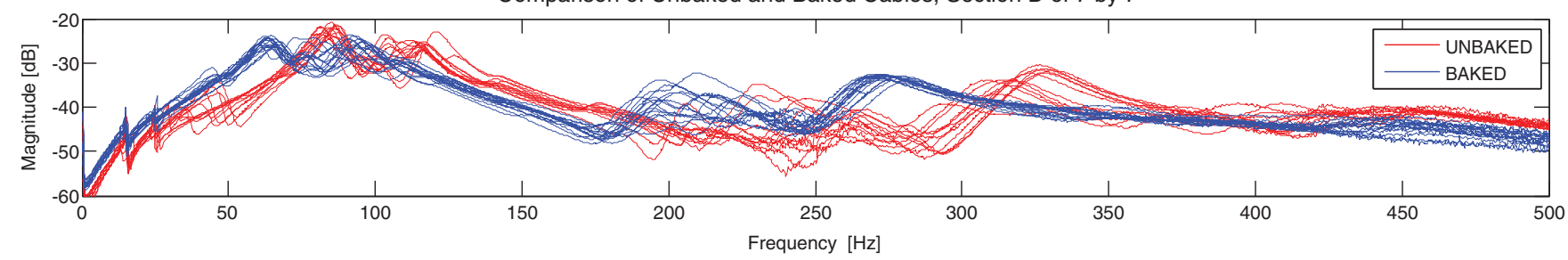

Fig. A4 Effect of bakeout treatment on frequency response of each test section of $7 \times 7$ cable. 


\section{Acknowledgments}

K. Spak thanks the NASA Space Technology Research Fellowship program for generous support and the Virginia Space Grant Consortium for additional funding as well as Southern California Braiding, Inc., for providing flight cables at cost. D. Inman gratefully acknowledges the support of U.S. Air Force Office of Scientific Research grant number FA9550-10-1-0427 monitored by David Stargel. Part of this research was carried out at the Jet Propulsion Laboratory, California Institute of Technology, under a contract with NASA.

\section{References}

[1] Ardelean, E. V., Goodding, J. C., Coombs, D. M., Griffee, J. C., Babuska, V., Robertson, L. M., and Lane, S. A., "Cable Effects Study: Tangents, Rat Holes, Dead Ends, and Valuable Results," 51st AIAA/ ASME/ASCE/AHS/ASC Structures, Structural Dynamics and Materials Conference, AIAA Paper 2010-2806, 2010.

[2] Coombs, D. M., Goodding, J. C., Babuska, V., Ardelean, E., Robertson, L. M., and Lane, S. A., "Dynamic Modeling and Experimental Validation of a Cable-Loaded Panel," Journal of Spacecraft and Rockets, Vol. 48, No. 6, 2011, pp. 958-973. doi: $10.2514 / 1.51021$

[3] Goodding, J. C., Ardelean, E. V., Babuska, V., Robertson, L. M., and Lane, S. A., "Experimental Techniques and Structural Parameter Estimation Studies of Spacecraft Cables," Journal of Spacecraft and Rockets, Vol. 48, No. 6, 2011, pp. 942-957. doi:10.2514/1.49346

[4] Babuska, V., Ardelean, E., Robertson, L. M., and Lane, S. A., "Modeling and Experimental Validation of Space Structures With Wiring Harness," Journal of Spacecraft and Rockets, Vol. 47, No. 6 , 2010, pp. 1038-1052. doi: $10.2514 / 1.48078$

[5] "Thermal Vacuum Bakeout Specification for Contamination Sensitive Hardware," NASA SPEC 1238:2007, George C. Marshall Space Flight Center, 2007.

[6] Costello, G. A., Theory of Wire Rope, 2nd ed., Springer, New York, 1997, pp. 1-25.

[7] Raoof, M., "Effect of Lay Angle on Various Characteristics of Spiral Strands," International Journal of Offshore and Polar Engineering, Vol. 7, No. 1, 1997, pp. 54-62.

[8] Inman, D. J., Engineering Vibration, Pearson Education, New Jersey, 2012, pp. 546-550.
[9] Yamaguchi, H., and Adhikari, R., "Energy-Based Evaluation of Modal Damping in Structural Cables With and Without Damping Treatment," Journal of Sound and Vibration, Vol. 181, No. 1, 1995, pp. $71-83$ doi:10.1006/jsvi.1995.0126

[10] Papailiou, K. O., "On the Bending Stiffness of Transmission Line Conductors," IEEE Transactions on Power Delivery, Vol. 12, No. 4 1997, pp. 1576-1588. doi: $10.1109 / 61.634178$

[11] Goodding, J. C., Babuska, V., Griffith, D. T., Ingram, B. R., and Robertson, L. M., "Study of Free-Free Beam Structural Dynamics Perturbations Due to Mounted Cable Harness," 48th AIAA/ASME/ ASCE/AHS/ASC Structures, Structural Dynamics and Materials Conference, AIAA Paper 2007-2390, 2007.

[12] Goodding, J. C., Griffee, J. C., and Ardelean, E. V., "Parameter Estimation and Structural Dynamic Modeling of Electrical Cable Harnesses on Precision Structures," 49th AIAA/ASME/ASCE/AHS/ASC Structures, Structural Dynamics and Materials Conference, AIAA Paper 2008-1852, 2008.

[13] Knapp, R. H., and Liu, X., "Cable Vibration Considering Interlayer Coulomb Friction," International Journal of Offshore and Polar Engineering, Vol. 15, No. 3, 2005, pp. 229-234.

[14] Ewins, D. J., Modal Testing: Theory, Practice and Application, 2nd ed., Research Studies Press Ltd., Baldock, England, U.K., 2000.

[15] Spak, K. S., Agnes, G. S., and Inman, D. J., "Toward Modeling of Cable Harnessed Structures: Cable Damping Experiments," 54th AIAA/ASME/ ASCE/AHS/ASC Structures, Structural Dynamics and Materials Conference, AIAA Paper 2103-1889, 2013.

[16] Jha, R., Pausley, M., and Ahmadi, G., "Optimal Active Control of Launch Vibrations of Space Structures," Journal of Spacecraft Rockets, Vol. 40, No. 6, 2003, pp. 868-874. doi:10.2514/2.7051

[17] "Ariane 5 User's Manual," No. 5, Rev. 1, Arianespace, EvryCourcouronnes, France, July 2011, p. 74.

[18] Raoof, M., and Davies, T. J., "Simple Determination of the Maximum Axial and Torsional Energy Dissipation in Large Diameter Spiral Strands," Computers and Structures, Vol. 84, Nos. 10-11, 2006, pp. 676-689. doi:10.1016/j.compstruc.2005.11.005

V. Babuska Associate Editor 